\title{
Ephrin-A3 Is Required for Tonotopic Map Precision and Auditory Function in the Mouse Auditory Brainstem
}

\section{Natalia Hoshino}

Loyola University Chicago

\section{Yazan Altarshan}

Loyola University Chicago https://orcid.org/0000-0002-2996-321X

\section{Ahmad Alzein}

Loyola University Chicago

\section{Amali Fernando}

Loyola University Chicago

\section{Hieu Nguyen}

Loyola University Chicago

\section{Emma Majewski}

Loyola University Chicago

\section{Vincent Chen}

Loyola University Chicago

\section{William Rochlin}

Loyola University Chicago

Wei-Ming Yu ( $\nabla$ wyu1@luc.edu )

Loyola University Chicago https://orcid.org/0000-0002-8408-2888

\section{Article}

Keywords: tonotopy, auditory brainstem, cochlear nucleus

Posted Date: March 11th, 2021

DOl: https://doi.org/10.21203/rs.3.rs-299438/v1

License: (c) (1) This work is licensed under a Creative Commons Attribution 4.0 International License. Read Full License

Version of Record: A version of this preprint was published at Journal of Comparative Neurology on July 7th, 2021. See the published version at https://doi.org/10.1002/cne.25213. 


\section{Abstract}

Tonotopy is a prominent feature of the vertebrate auditory system and forms the basis for sound discrimination, but the molecular mechanism underlying its formation remain largely elusive. Ephrin/Eph signaling is known to play important roles in axon guidance during topographic mapping in other sensory systems. Here, we determined that ephrin-A3 molecules are expressed in a ventral to dorsal descending gradient along the tonotopic axis in developing mouse cochlear nucleus. During cochlear nucleus innervation by auditory nerve fibers, ephrin-A3 forward signaling can repel these fibers in a stagedependent manner. In ephrin-A3 mutant animals, the tonotopic map is degraded and isofrequency bands of neuronal activation become imprecise in the anteroventral cochlear nucleus. Ephrin-A3 mutants also exhibit a delayed second wave in auditory brainstem responses and impaired detection sound frequency changes. Our findings establish an essential role for ephrin-A3 in forming precise tonotopy in the auditory brainstem to ensure accurate sound discrimination.

\section{Introduction}

Tonotopy is the most fundamental organizing principle of the vertebrate auditory system, meaning cells of the auditory pathway are topographically arranged by their responses to different sound frequencies ${ }^{1}$. Tonotopy allows animals to separate a complex sound into its frequency components, forming the basis for sound discrimination. Tonotopy originates from the orderly coding of high-frequency sound to lowfrequency sounds by auditory hair cells along the basal to apical axis of the inner ear cochlea. Each hair cell then activates a small subset of spiral ganglion neurons (SGNs), which in turn extend and bifurcate their auditory nerve fibers (ANFs) to innervate neurons in the three subdivisions of the brainstem cochlear nucleus $(\mathrm{CN})$ in a tonotopic fashion ${ }^{2}$. SGNs responding to high frequency sounds at the base of the cochlea project their ANFs to the dorsal portions of the dorsal cochlear nucleus (DCN), the posteroventral cochlear nucleus (PVCN), and the anteroventral cochlear nucleus (AVCN). In contrast, SGNs that convey information of low frequency sounds at the cochlear apex send their fibers to the ventral parts of the $\mathrm{DCN}, \mathrm{PVCN}$, and the $\mathrm{AVCN}^{3}$. This tonotopic connectivity allows ANFs with similar frequency preference to terminate within the $\mathrm{CN}$ to form well-defined isofrequency bands where nearby $\mathrm{CN}$ neurons are selectively activated by similar sound frequencies ${ }^{4}$ (Fig. 1).

In the developing cochlea, the central processes of ANFs innervate the $\mathrm{CN}$ in a developmental gradient according to tonotopy ${ }^{5}$. In mice, SGNs are born in a basal to apical progression along the length of the cochlea, with neurons in the base (future high-frequency preference) born early around mouse embryonic day (E) 9.5-10.5 and those in the apex (future low-frequency preference) born later, around E12.5 to $13.5^{6-}$ 9 . This sequential neurogenesis of SGNs results in ANFs from the early-born basal SGNs initiating outgrowth about 2-3 days earlier than ANFs from the late-born apical SGNs. The early-arriving basal ANFs invade the developing $\mathrm{CN}$ by E13.5 $5^{5}$, just as the $\mathrm{CN}$ anlage is starting to emerge. In mice, most neurons in the AVCN and PVCN are born between E10.5 to E13.5 and neurogenesis of these two CN subdivisions is complete by E14.5-11. In contrast, neurogenesis of the DCN occurs in two waves. In the DCN, principal 
excitatory neurons are born in the first wave between E10.5 and E13.5 and small local circuit neurons are born in the second wave beginning on E14.5 and lasting until the early postnatal stages. Despite continuous neurogenesis of the DCN, afferent innervation of ANFs in the $\mathrm{CN}$ is already organized into a coarse tonotopic map by E15.5 5,6. Future high-or low-frequency responsive ANFs are found to target to different areas in the immature $\mathrm{CN}$ anlage. This suggests that the emergence of tonotopic maps in the $\mathrm{CN}$ is developmentally hardwired by molecular cues. Subsequently, spontaneous neuronal activity that occurs prior to sensory experience and neuronal activity that results from hearing play essential roles in axon and synapse refinement to give rise to the high tonotopic precision in the mature circuits ${ }^{12-15}$. Despite the importance of tonotopy in auditory function, to date, the molecular mechanisms that underlie formation of tonotopic maps in central auditory circuits remain largely elusive.

A degraded tonotopic map in the auditory brainstem has been observed in mice carrying mutations in several molecules, including the receptor guanylyl cyclase Npr2, transcription factor Hox2, transcription factor NeuroD1, prickle planar cell polarity protein 1, and the a9 subunit of nicotinic acetylcholine receptors ${ }^{13,16-19}$, but this is thought to result from defects in neuronal differentiation, axon outgrowth, or altered neuronal activity. To begin our investigation of axon guidance signaling mechanisms that could be important in tonotopy, we focused on ephrins and Ephs. Ephrins and Ephs are cell-cell recognition molecules that usually show graded expression and play important roles in axon pathfinding and targeting during neural development ${ }^{20,21}$. Depending on their structures and how they associate with the cell membrane, ephrins can be divided into two subclasses: ephrin-A and ephrin-B. Five mammalian ephrin-As (ephrin-A1-5, and ephrin-A6 in chicken) and three mammalian ephrin-Bs (ephrin-B1-3) have been identified. Ephrin-As do not have a transmembrane domain but are anchored to the plasma membrane with a glycosylphosphatidylinositol (GPI) anchor. In contrast, ephrin-Bs possess a single-pass hydrophobic transmembrane domain and a short, highly conserved cytoplasmic tail. Ephrins interact with a group of receptors called Ephs. 16 identified Eph receptors constitute the largest known family of receptor tyrosine kinases, which are also divided into two subclasses, EphA or EphB, according to their sequence similarity and binding affinity for either the ephrin-A or the ephrin-B ligands. 10 EphAs (EphA110) primarily bind to ephrin-As and 6 EphBs (EphB1-6) mainly interact with ephrin-Bs. The interactions between Eph receptors and ephrin ligands within each subclass are promiscuous, as Eph receptors of a particular subclass can bind with various affinities to all ephrin ligands in the corresponding subclass. A few exceptions of cross-binding of Ephs to ephrins of the opposing subclass have also been reported. Although Ephs are referred to as receptors and ephrins are viewed as ligands, both can initiate signaling cascades: forward signaling when Ephs are the receptors, and reverse signaling when Ephs are the ligands. As ephrins and Ephs are expressed on the cell surface, activation of ephrin-Eph signaling only occurs at sites of close cell-cell interaction, allowing highly specific spatial instruction ${ }^{22}$. One of the most well-established roles of ephrin/Eph interactions is their involvement in topographic map formation in the visual system ${ }^{23}$. Ephrins and Ephs are distributed in complementary gradients across different anatomical axes in the retina and superior colliculus. These gradients result in matching levels of specific ephrins and Ephs, facilitating topographic termination of retinal ganglion axons in specific zones within the superior colliculus. Ephrin-Eph signaling was first implicated in tonotopic map formation by the 
pioneering studies of Cramer et al. ${ }^{24-28}$. In chicken embryos, multiple ephrins and Ephs show graded expression in the cochlear ganglion, eighth nerve, and auditory brainstem nuclei. Misexpression of EphA4 in the developing chicken auditory brainstem results in reduced precision of the tonotopic map. In EphA4and ephrin-B2-deficient mice, they respond to sounds with decreased sensitivity and increased latency and exhibit altered neuronal $c$-fos activation in auditory brainstem nuclei upon pure tone exposure. These findings suggest a potential involvement of ephrin-Eph signaling in formation of tonotopic maps.

To further explore if ephrins and Ephs are involved in tonotopic map formation in the central auditory system, we began with an expression screen of the ephrin-A subclass members. We found that during development, ephrin-A3 molecules show graded expression in mouse $\mathrm{CN}$ and they repel growing ANFs in a stage-dependent manner. In the absence of ephrin-A3, mutant mice have a degraded tonotopic map and an altered auditory activation pattern in the AVCN, leading to impaired ability to detect sound frequency changes. These results establish an essential role for ephrin-A3 in formation of tonotopic maps in the $\mathrm{CN}$.

\section{Results}

\section{Ephrin-A3 is expressed in a ventral to dorsal descending gradient in the developing $\mathrm{CN}$}

Expression of ephrin-As were determined in the $\mathrm{CN}$ during the emergence of tonotopic maps at E15.5 and E17.5. Because cell surface molecules, such as ephrins and Ephs, are usually expressed at low levels, we used RNAScope ${ }^{\circledR}$ in situ hybridization, a procedure that allows us to detect expression of low-abundance RNA transcripts semi-quantitatively.

At E15.5, the $\mathrm{CN}$ anlage is still quite immature as DCN cells continue to proliferate and the DCN is fully caudal to the VCN. Shortly after this stage, the hindbrain flexes, resulting in the DCN shifting dorsal to the VCN. By analyzing expression of ephrin-As in the CN anlage on E15.5 and E17.5, we found that ephrin-A1 is not expressed in the $\mathrm{CN}$ and ephrin-A4 is expressed in the eighth nerve root but not inside the $\mathrm{CN}$ (data not shown). Ephrin-A2 and -A5 are expressed uniformly at low levels in the CN anlage (Fig. 2a, b, e, f; VCN anlage shown on E15.5 and AVCN anlage shown on E17.5 in all panels). Of all ephrin-As, ephrin-A3 expression is particularly interesting. Ephrin-A3 is expressed in a ventral to dorsal descending gradient along the tonotopic axis in the $\mathrm{CN}$ anlage, with future lower-frequency regions showing greater expression than future higher-frequency regions (Fig. 2c, d). To validate the specificity of ephrin-A3 expression signals, we performed in situ hybridization of ephrin-A3 on tissues from ephrin- $A 3^{-/-}$mice. No ephrin-A3 expression signals were detected in ephrin- $A 3^{-/-} \mathrm{CN}$ anlage (Fig. $2 \mathrm{~g}, \mathrm{~h}$ ), confirming the specificity of ephrin-A3 probes. Moreover, ephrin-A3 was found to be predominately expressed by Atoh1-derived Mafbpositive bushy cells ${ }^{36,37}$, the principal output neurons of the AVCN (Fig. 2i-p). We also observed that ephrin- $A 3$ is expressed much higher in the $\mathrm{CN}$ than in the cochlea at these stages (data not shown), so we decided to focus our studies first on the role of ephrin-A3 forward signaling (ephrin-A3 ligands in CN activating Eph receptors in SGN afferents) during tonotopic map formation in the $\mathrm{CN}$.

\section{Ephrin-A3 forward signal repels ANFs in a developmental stage-dependent manner}


Since ephrin-A3 shows an intriguing expression pattern in the $\mathrm{CN}$ during development, we developed an ephrin-A3 stripe assay using cochlear ganglion explants to determine whether ephrin-A3 molecules mediate any guidance effects on growing ANFs when they innervate $\mathrm{CN}$.

E15.5 and 17.5 mouse cochleae were isolated and divided into pieces to establish the explants. To compare whether ANFs from the base and the apex of the cochlea have different responses to ephrin-A3, cochlear explants were prepared by using a one-third turn of the cochlea from either the most basal (contain mostly future high-frequency ANFs) or the most apical aspect (contain mostly future lowfrequency ANFs) of the cochlea. To allow us to distinguish peripheral processes of SGNs from their central processes and to help us better orient the cochlear ganglion explants, we preserved the sensory epithelium in our explant culture system and used myosin VI staining to mark the developing auditory hair cells. At E15.5, hair cells just start to differentiate so myosin VI antibodies only label inner hair cells in the base but not the apical inner hair cells nor all outer hair cells. By E17.5, one row of inner hair cells and 3-4 rows of outer hair cells could be visualized by myosin VI staining in all regions of the cochlea (Fig. 3a, b). In our explant culture system, we used neurofilament/GAP43 staining to reveal growing ANFs and found that the peripheral processes of ANFs were still preserved, but their staining intensity is much weaker than the intensity of central processes. Peripheral processes can only be visualized at a magnification higher than 600X as shown in Fig. 3b. This allows us to easily distinguish the central processes of ANFs from their peripheral processes with confidence and use this system to test the responses of growing ANFs in the CN to ephrin-A3.

Control coverglasses were coated with alternating stripes of Alexa Fluor 488-labeled and unlabeled human IgG-Fc. ANFs from basal or apical cochlear ganglia obtained at E15.5 or E17.5 showed no preference for either stripe on control coverglasses (Fig. 3c, d). On the experimental coverglasses, ANFs from E15.5 ganglia emitted in parallel to ephrin-A3 stripes and grew significantly less on the ephrin-A3-Fc stripes than control stripes if 10,20, and $40 \mu \mathrm{g} / \mathrm{ml}$ ephrin-A3-Fc, but not $2 \mu \mathrm{g} / \mathrm{ml}$ ephrin-A3-Fc, was used to prepare the test stripe (Fig. 3e, g, i, k, m). We also found that ANFs from basal and apical ganglia exhibited a comparable response to ephrin-A3 repulsion (Fig. 3k, m). Since basal and apical ANFs were similarly repelled by ephrin-A3 forward signaling, we provide representative images only from experiments of the apical ganglia (Fig. 3c-j). On the experimental coverglasses using E17.5 cochlear explants, ANFs showed a decreased response to ephrin-A3 repulsion. E17.5 ANFs were no longer repelled by stripes containing $10 \mu \mathrm{g} / \mathrm{ml}$ ephrin-A3-Fc and could only be repelled by stripes containing $40 \mu \mathrm{g} / \mathrm{ml}$ ephrin-A3-Fc (Fig. 3f, h, j, I, n). Again, both basal and apical ANFs from E17.5 cochlear ganglia demonstrated a similar developmentally reduced response to ephrin-A3 repulsion, although the response was reduced more in basal than in apical ANFs (Fig. 3l, n). Apical but not basal ANFs could still be moderately repelled by stripes containing $20 \mu \mathrm{g} / \mathrm{ml}$ ephrin-A3-Fc (Fig. 3n). Statistical analyses were used to compare the ephrin-A3 repulsive responses between ANFs from basal and apical ganglia and between ANFs from E15.5 and E17.5 ganglia. ANFs from basal and apical ganglia showed no significant difference in their responses to ephrin-A3 repulsion [two-way ANOVA, E15.5: basal vs. apical, $F_{(1,46)}=$ $0.000645, p=0.98$; $E 17.5$ : basal vs. apical, $\left.F_{(1,39)}=0.2069, p=0.65\right]$. The stage dependent change in 
sensitivity to the repulsive influence of ephrin-A3-Fc stripes was significant, the E15.5 ANFs were more sensitive than the E17.5 ANFs [two-way ANOVA, basal ganglia: E15.5 vs. E17.5, $F_{(1,43)}=7.431, p=0.0092$; apical ganglia: $E 15.5$ vs. E17.5, $\left.F_{(1,42)}=4.137, p=0.0483\right]$. Post-hoc Welch's unequal variances t-test demonstrated that both basal and apical ANFs from E15.5 ganglia could be strongly repelled by stripes containing 10, 20, or $40 \mu \mathrm{g} / \mathrm{ml}$ ephrin-A3-Fc [basal: $2 \mu \mathrm{g} / \mathrm{ml}(\mathrm{p}=0.82), 10$ to $40 \mu \mathrm{g} / \mathrm{ml}(\mathrm{p}<0.005)$; apical: 2 $\mu \mathrm{g} / \mathrm{ml}(\mathrm{p}=0.75), 10$ to $40 \mu \mathrm{g} / \mathrm{ml}(\mathrm{p}<0.008)]$ (Fig. 3k, m), but E17.5 ANFs could only be strongly repelled by stripes containing $40 \mu \mathrm{g} / \mathrm{ml}$ ephrin-A3-Fc [basal: $2 \mu \mathrm{g} / \mathrm{ml}$ ( $p=0.76), 10 \mu \mathrm{g} / \mathrm{ml}(\mathrm{p}=0.27), 20 \mu \mathrm{g} / \mathrm{ml}(\mathrm{p}=$ $0.056), 40 \mu \mathrm{g} / \mathrm{ml}\left(p=4.23 \times 10^{-5}\right) ;$ apical: $2 \mu \mathrm{g} / \mathrm{ml}(p=0.84), 10 \mu \mathrm{g} / \mathrm{ml}(p=0.12), 20 \mu \mathrm{g} / \mathrm{ml}(p=0.048), 40$ $\mu \mathrm{g} / \mathrm{ml}(\mathrm{p}=0.0002)]$ (Fig. $3 \mathrm{l}, \mathrm{n})$. This developmental reduction in sensitivity to ephrin-A3 repulsion could have a potentially interesting role in establishing $\mathrm{CN}$ tonotopy given that central processes of SGNs innervate $\mathrm{CN}$ in a developmental gradient according to tonotopy ${ }^{5}$. Future high-frequency ANFs from basal SGNs arrive in the CN 2 to 3 days earlier than future low-frequency ANFs from apical SGNs. An intermediate to high concentration of ephrin-A3 in the ventral part of the $\mathrm{CN}$ may prevent future highfrequency fibers stabilizing their terminals in this territory and target to regions more dorsally, analogous to what happens in retinocollicular mapping of the visual system ${ }^{38} .2-3$ days later, the decreased sensitivity to ephrin-A3 in ANFs may allow terminals of late-arriving apical ANFs to innervate the ventral region of the $\mathrm{CN}$.

\section{Reduced precision of tonotopic inputs from ANFs in the ephrin- $A 3^{-/-}$mutant AVCN}

We next asked whether ephrin-A3 is required in the $\mathrm{CN}$ to organize tonotopic precision of ANF inputs. We used mice lacking ephrin-A3 to address our questions. Paper strips coated with NeuroVue ${ }^{\circledR}$ red and maroon dyes were inserted into the mid-basal and apical turns of the cochlea in E18.5 heads. The dye was allowed to diffuse anterogradely through ANFs to the hindbrain. This enables us to trace innervation of distinct subsets of ANF inputs in the CN. For each tracing, the fraction of the AVCN area innervated by

dye-labeled ANFs from the mid-basal or apical cochlear turn $\left[\left(S_{m b} / S_{A V C N} \times 100\right)\right.$ or $\left.\left(S_{a} / S_{A V C N} \times 100\right)\right]$ was normalized to the dye angular spread in the corresponding cochlear turn $\left(\theta_{\mathrm{mb}}\right.$ or $\left.\theta_{\mathrm{a}}\right)$ to obtain $\left(\mathrm{S}_{\mathrm{mb}} / \mathrm{S}_{\mathrm{AVCN}}\right.$ $\times 100) / \theta_{\mathrm{mb}}$ or $\left(\mathrm{S}_{\mathrm{a}} / \mathrm{S}_{\mathrm{AVCN}} \times 100\right) / \theta_{\mathrm{a}}$.

In littermate controls, SGN afferents traced from the mid-basal or apical turn targeted to topographically distinct regions in the developing AVCN along the tonotopic axis (Fig. 4a). The gross tonotopic targeting

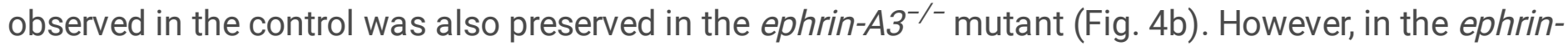
$A 3^{-/-}$mutant, the dye tracing from ANFs was more diffuse when compared to the control (Fig. 4a, b). In

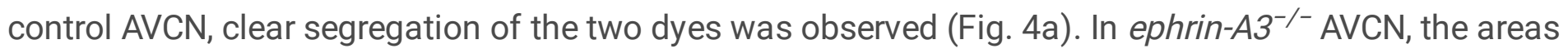
targeted by ANFs labeled with the two dyes were adjacent to each other with very little segregation (Fig. 4b). Welch's unequal variances t-tests revealed that mid-basal ANFs innervated $\sim 24 \%$ more area in ephrin-A3 ${ }^{-/-}$AVCN than in control AVCN $(p=0.03)$, and apical ANFs targeted $\sim 70 \%$ more area in ephrin-

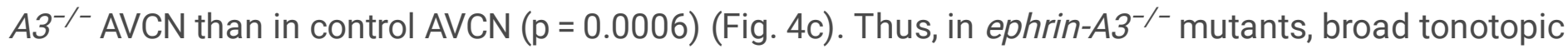
segregation is maintained but precision of the tonotopic map is degraded at birth. 


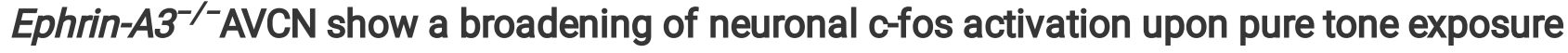

In postnatal development, neuronal connectivity in the coarse tonotopic map undergoes axon refinement and synapse elimination to sharpen isofrequency bands and achieve high tonotopic resolution in the mature circuits ${ }^{12-15}$. Degraded precision of tonotopic inputs from perinatal mutant ANFs raised the question of whether imprecise tonotopic connectivity may impair postnatal refinement and diminish tonotopic map resolution in adult ephrin- $A 3^{-/-}$mutants. To test this possibility, we exposed awake, freely moving 5-7-week-old mice to $16-\mathrm{kHz}$ tone pips, $8-\mathrm{kHz}$ tone pips, or simultaneous 16 - and 8-kHz tone pips at $75 \mathrm{~dB}$ SPL for $90 \mathrm{~min}$ and evaluated induction of the immediate early gene $c$-fos by calculating the percentage of $c$-fos-positive area in the AVCN from the section containing the largest AVCN area. The

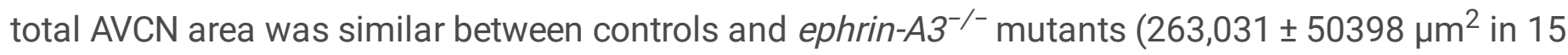
controls vs. $268,667 \pm 79401 \mu \mathrm{m}^{2}$ in 15 mutants, $p=0.82$, Welch's t-test), suggesting that AVCN size was not affected in ephrin- $A 3^{-/-}$mutants. In controls, $c$-fos-positive isofrequency bands could be observed at different zones along the tonotopic axis in the AVCN upon pure tone exposure at $16-\mathrm{kHz}$ or $8-\mathrm{kHz}$ (Fig. $5 \mathrm{a}$,

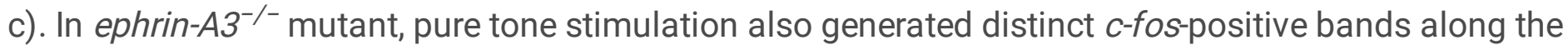
tonotopic axis in the AVCN but these $c$-fos-positive bands became broader in mutants than in controls (Fig. 5b, d). Furthermore, simultaneous stimulation of alternating $16-\mathrm{kHz}$ and $8-\mathrm{kHz}$ tone pips induced two distinct segregated $c$-fos-positive bands in control AVCN but the same stimulation generated two

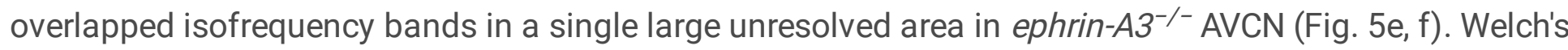
$\mathrm{t}$-tests showed that $16-\mathrm{kHz}$ or $8-\mathrm{kHz}$ stimulation generated approximately twice larger c-fos-positive area in ephrin-A3 ${ }^{-/-}$than in control AVCN ( $p<0.001$ for $16-\mathrm{kHz}$ or $8-\mathrm{kHz}$ stimulation) and simultaneous 16 - and $8-\mathrm{kHz}$ stimulation resulted in a separation zone between two c-fos-positive bands around three times

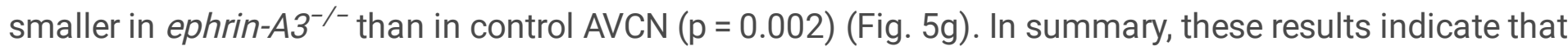
in the absence of ephrin-A3, auditory activation patterns are changed and the tonotopic specificity is degraded in the AVCN.

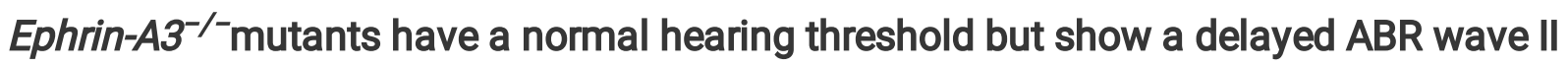

Mice with defects in peripheral auditory circuits are known to have diminished auditory sensitivity, but mice with degraded tonotopic precision have been shown to have apparently normal hearing ${ }^{18}$. To determine whether hearing is affected in ephrin- $A 3^{-/-}$mutants with impaired tonotopy, we compared auditory brainstem responses (ABRs) between 5-7-week-old control and ephrin- $A 3^{-/-}$mutant mice in response to 7 pure tone pips from $5.6-45.2 \mathrm{kHz}$. ABRs reflect the electrical responses of neurons in the cochlea and auditory brainstem to sound stimuli. The first wave of ABRs (wave I) reflects the synchronously firing of SGN axons and the second wave (wave II) reflects the synchronously firing of globular cells near the eighth nerve root in the $\mathrm{VCN}^{39}$.

Both control and ephrin- $A 3^{-/-}$mice produced characteristic ABR waveforms in response to all stimuli

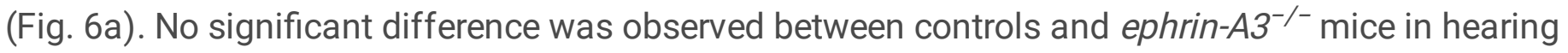
thresholds [two-way ANOVA, $F_{(1,91)}=0.6836, p=0.41$ ], or the amplitude and latency of wave $I$ in response 
to $8-22.6 \mathrm{kHz}$ tones at $90 \mathrm{~dB}$ SPL (Welch's t-test, $\mathrm{p}>0.1$ ) (Fig. 6b, c, e). This indicates that the function of the peripheral circuit in the cochlea is not affected in ephrin- $A 3^{-/-}$mice. In line with this, we also did not observe obvious connectivity defects or changes in gross cellular organization in adult ephrin-A3-/cochlea (data not shown). However, the second wave of ABRs was delayed in ephrin- $A 3^{-/-}$mutants in response to $8-22.6 \mathrm{kHz}$ tones at $90 \mathrm{~dB} S P L(p<0.02)$, although its amplitude appears normal when compared to controls $(p>0.4)$ (Fig. $6 d, f)$. The increased latency of the wave ll suggests that degraded tonotopic precision of ANF inputs may lead to asynchronous firing in some VCN neurons.

\section{Ephrin- $A 3^{-/-}$mutants fail to discriminate sounds with small frequency changes}

Although ephrin- $A 3^{-/-}$mutants are still able to respond to sounds with normal sensitivity, they may have subtle deficits in processing sound information. In mice lacking the a9 subunit of nicotinic acetylcholine receptors, mutant mice have normal tone detection and auditory threshold, but they exhibit deficits in frequency discrimination due to a degraded tonotopic map in lateral superior olive ${ }^{13}$. To explore whether decreased tonotopic precision in ephrin- $A 3^{-/-}$mutants could result in a similar functional defect, we used prepulse inhibition of the acoustic startle response (ASR) to assess sound frequency discrimination as described previously ${ }^{33-35}$. The ASR is a reflexive motor response to an unexpected loud sound that presents as a rapid contraction of skeletal muscles. In mice, ASR is measured by placing the animal on a platform that transmits the downward force produced by the reflex. The ASR is attenuated when a weak prepulse sound is presented just before the startle-eliciting loud sound, a condition termed prepulse inhibition (PPI). PPI depends on the animal's ability to detect and process the prepulse sound, so it provides a useful method to assess sound frequency discrimination. 7 prepulse tones ranging from 15.92 $\mathrm{kHz}$ to $12 \mathrm{kHz}$ were used to test the animal's ability to discriminate them from a $16 \mathrm{kHz}$ background tone.

No significant difference of body weight was found between 5-7-week-old controls and ephrin-A3-/mutants ( $19.55 \pm 1.35 \mathrm{~g}$ in 8 controls vs. $19.29 \pm 2.66 \mathrm{~g}$ in 6 mutants, $p=0.81$, Welch's t-test), suggesting ephrin- $A 3^{-/-}$mutants should generate a downward force comparable to controls if their ASR is normal. Both control and ephrin-A3/-- mice showed a similar ASR in response to the startle stimulus. The average ASR amplitude was not significantly different between the two groups [2.00 \pm 0.22 arbitrary units (AU) in 8 controls vs. $2.10 \pm 0.25 \mathrm{AU}$ in 6 mutants, $p=0.47$, Welch's t-test] (Fig. 7f, g, I), indicating that the function

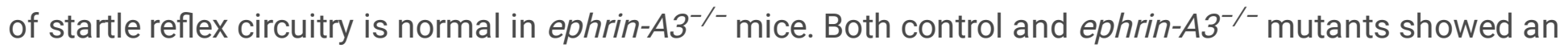
inhibition of the ASR when the startle stimulus is preceded by a frequency shift from the background frequency. The inhibition increased when the magnitude of the frequency change increased and plateaued around $60 \%$ inhibition for a frequency shift around $16.6 \%$ (Fig. $7 \mathrm{~m}$ ). However, PPI elicited by small negative frequency changes (0.5-5\%) was significantly reduced in ephrin- $A 3^{-/-}$mutants compared to controls [two-way ANOVA, $F_{(1,84)}=29.29, p<0.0001$; post-hoc Welch's t-test, $p<0.05$ for all frequency changes between $0.5-5 \%$ ] (Fig. 7h, i, I, m). Additionally, the frequency discrimination threshold (defined as the smallest frequency change that elicited a significant inhibition of the ASR when compared to inhibition elicited by no frequency change using one-way Welch's t-test) was elevated in ephrin- $A 3^{-/-}$ mutants compared to controls. The smallest frequency change, $0.5 \%$, could already elicit a significant 
inhibition in controls $(p=0.01)$. By comparison, the ASR of ephrin- $A 3^{-/-}$mutants was not significantly inhibited until the frequency change of the prepulse tone reached $3.3 \%[0.5-2 \%(p>0.15), 3.3 \%(P=$ 0.001)] (Fig. 7m). As PPI elicited by large frequency changes (10-25\%) was still similar between controls and ephrin- $A 3^{-/-}$mutants (Fig. 7j-m), it is unlikely that reduced PPI elicited by small frequency changes in mutants is caused by changes in circuitry that mediates PPI. Therefore, the ability of ephrin- $A 3^{-/-}$mice to detect sound frequency changes was impaired, consistent with the observation of an altered $c$-fos activation pattern.

\section{EPHA Receptors Are Expressed In Developing SGNS}

Ephrin-As primarily interact with EphA receptors to activate forward signaling. Ephrin-A3 is known to bind to all 10 EphAs with different binding affinities. To determine potential EphA receptors in SGNs which could mediate ephrin-A3 repulsive effects, we performed a pilot RNA-Seq experiment to detect which EphA receptors are expressed at a high level in E16.5 cochleae. Of the 10 EphAs, EphA4 and EphA7 are expressed at higher levels than other EphAs, with a FPKM value greater than 10 (EphA4: 13 FPKM, EphA7: 42 FPKM from one pilot RNA-seq experiment of extracts from 8 cochleae). To assess whether EphA4 and EphA7 are expressed in developing SGNs, we conducted RNAScope ${ }^{\circledR}$ in situ hybridization in E15.5 and E17.5 cochleae.

EphA4 was broadly expressed in many regions of the cochlea at these stages, including mesenchyme, the cochlear epithelium, and the spiral ganglion (Fig. 8a, a', c, c'). In the spiral ganglion, EphA4 levels varied among neurons at E15.5 but became more uniform at E17.5 (Fig. 8a, c). EphA7 was present more locally in the cochlea, with high expression in the cochlear epithelium and moderate expression in the spiral ganglion (Fig. 8b, b', d, d'). EphA7 expression is relatively uniform among E15.5 SGNs but slightly downregulated in the middle and basal regions of the ganglion at E17.5 (Fig. 8b, d). Altogether, these results are consistent with previous observations ${ }^{40,41}$. The spatially and temporally complementary expression of EphA4 and EphA7 in SGNs and ephrin-A3 in CN also suggest that these Eph receptors might play a role in mediating ephrin-A3 effects in the developing $\mathrm{CN}$.

\section{Discussion}

Here, we demonstrate that ephrin-A3 molecules show graded expression in the $\mathrm{CN}$, and their absence disrupts tonotopic mapping, acoustic processing, and sound discrimination. Together, our findings suggest a model for how ephrin-A3 might influence tonotopic map formation in the CN (Fig. 9). Ephrin-A3 is expressed in the $\mathrm{CN}$ in a ventral to dorsal descending gradient during the emergence of the tonotopic map. Correspondingly, ANFs innervate $\mathrm{CN}$ in a developmental gradient during these stages. Future highfrequency ANFs from early-born basal SGNs start to invade the CN from the ventral side around 2-3 days earlier than future low-frequency ANFs from the late-born apical SGNs. Ephrin-Eph signaling only occurs at sites of close cell-cell interaction to mediate axon targeting at choice points. When early-arriving basal ANFs navigate into the ventral part of the $\mathrm{CN}$, an intermediate to high concentration of ephrin-A3 prevents axon terminals stabilizing on neurons in this region, similar to the mechanism used in retinocollicular 
mapping of the visual system ${ }^{38}$, so these future high-frequency ANFs continue grow toward the dorsal end. 2-3 days later, future low-frequency ANFs arrive ventral $\mathrm{CN}$ and are no longer strongly sensitive to ephrin-A3 due to a developmentally reduced response to ephrin-A3, allowing them to maintain their terminals on neurons in this territory and innervate the ventral region. In the absence of ephrin-A3, highfrequency ANFs may terminate in regions more ventrally in the $\mathrm{CN}$, causing a degraded tonotopic map and impaired sound discrimination in mutant animals.

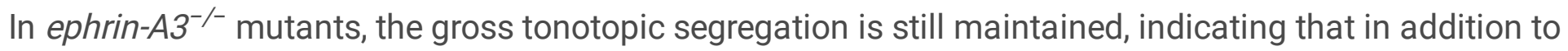
ephrin-A3, other guidance molecules are also involved in regulating tonotopic mapping in the $\mathrm{CN}$. Indeed, in the visual system, in order to orchestrate the formation of precise topographic maps of the retinocollicular projections, multiple ephrin and Eph molecules are expressed in complementary gradients in the retina and superior colliculus ${ }^{23}$. A similar mechanism could be employed by the auditory system to establish tonotopic maps. Other ephrins or Eph molecules could be expressed in a dorsal to ventral descending gradient complementary to ephrin-A3 to restrict future low-frequency ANFs to target to the dorsal region of the developing $\mathrm{CN}$. Concordantly with this, in addition to ephrin-A3, several ephrins and Ephs show high expression in the developing rhombomeres between E15.5 and E18.5, including ephrinB2/B3, EphA4/A5/A8/A10, and EphB1/B2 (Allen Mouse Brain Atlas). Ephrin-B2 and EphA4 are also demonstrated to be necessary for accurate auditory activation patterns in the $\mathrm{CN}$ and several ephrin/Eph mutant mice exhibit altered auditory brainstem responses ${ }^{26,27,42}$. Furthermore, other diffusible axon guidance molecules are also needed to serve as long-range cues to guide future high-frequency or lowfrequency ANFs to grow toward the dorsal end or stay in the ventral side of the CN. How these ephrins and Eph receptors influence tonotopic map formation and whether other families of axon guidance molecules also participate in the process require more future studies to elucidate.

We observed a developmentally reduced sensitivity to ephrin-A3 in ANFs. One possibility that may explain the decreased response to ephrin-A3 is downregulation of EphA receptors in SGNs during development. We detected expression of EphA4 and EphA7 in developing SGNs. Both receptors are differentially expressed at various levels among SGN populations during development. Expression of EphA7 is particularly interesting. EphA7 is uniformly expressed among SGNs at E15.5 but slightly downregulated in the middle and basal portion of the spiral ganglion at E17.5. This downregulation of EphA7 happens concurrently with the reduction of ephrin-A3 repulsion. EphA4 expression is also known to be regulated by the Pou3f 4 transcription factor in the cochlea ${ }^{40}$. Another possibility that could lead to an altered response to ephrin-A3 is endocytosis of EphA receptors, which has been observed during development of the retinocollicular topographic map ${ }^{43}$. Other mechanisms that could account for the reduced response to ephrin-A3 are a negative regulation of Eph receptors by protein tyrosine phosphatases ${ }^{44}$ or a downregulation/negative regulation of intracellular signaling effectors ${ }^{45}$. Whether EphA4 and EphA7 receptors are involved in mediating responses of ANFs to ephrin-A3 and how these receptors are regulated transcriptionally, post-transcriptionally, or post-translationally to modulate ephrin-A3 effects are currently under investigation. 
Homeodomain (Hox) transcription factors are known to be one of the key regulators of Eph receptor expression. In mice lacking Hoxa2 and Hoxb2 genes in AVCN neurons, mutant mice presented structural and functional defects that were very similar to those observed in ephrin- $A 3^{-/-}$mutants ${ }^{19}$. Hox 2 mutants also exhibit a degraded tonotopic map, an altered auditory c-fos activation pattern, and impaired sound frequency discrimination. In addition to Hox transcription factors, classical morphogens, such as Wnt proteins, have been shown to regulate the expression of ephrins/Ephs in mediating intestinal epithelial cell positioning or medial-lateral retinocollicular topographic mapping ${ }^{46,47}$. These observations suggest that anterior-posterior positional cues from distinct Hox genes may orchestrate the non-uniformly distributed morphogens to establish the graded expression of ephrins/Ephs in proper locations during tonotopic mapping in the auditory brainstem.

Finally, developmental perturbations in the central auditory pathway frequently result in central auditory processing disorders (CAPDs), a heterogeneous group of conditions estimated to affect 2 to $3 \%$ of children with no known cause ${ }^{48}$. Ephrin- $A 3^{-/-}$mutant mice have normal hearing sensitivity but exhibit

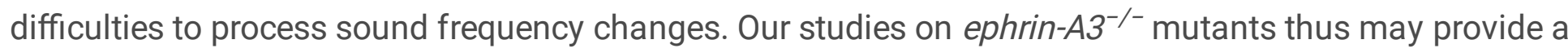
useful animal model to help us elucidate the pathogenesis of these disorders.

\section{Methods}

\section{Mice}

All animal experiments in this study have been performed in compliance with institutional and National Institutes of Health guidelines approved by the Institutional Animal Care and Use Committee at Loyola University Chicago (Protocol 1926).

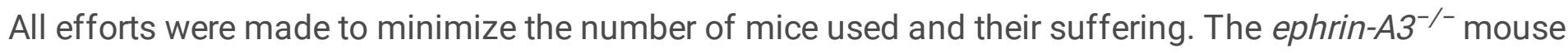
strain was obtained from the Jackson Laboratory (Stock Number: 019108) and has been described and validated previously ${ }^{29}$. Mice were maintained on the C57/BL6 background. Breeding pairs used were

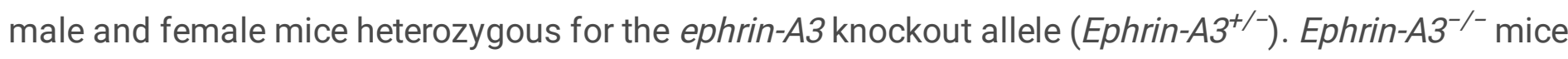
were PCR genotyped using the EphrinA3.F forward primer (5'-TGT GGG CGT GAC TAA GAT TG-3'), the E1.R reverse primer (5'-CAC TGC TGA TTG GAG CTG TTC-3'), and the YFP.R reverse primer (5'-GAA CTT CAG GGT CAG CTT GC-3') (wt, 250 bps; ephrin-A3 knockout allele, 350 bps). Both male and female mice were used in the experiments. As we did not observe haploinsufficiency phenotypes or major differences in the auditory system between Ephrin- $A 3^{+/+}$and Ephrin- $A 3^{+/-}$, both wild-type $\left(E p h r i n-A 3^{+/+}\right)$and

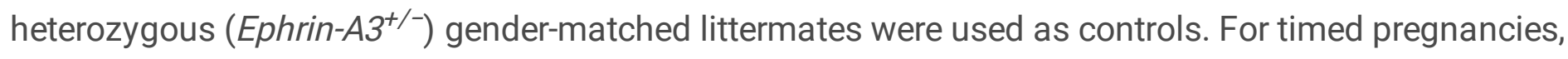
male and female mice were put together at $5 \mathrm{PM}$ and checked for the presence of a vaginal plug the following morning at $9 \mathrm{AM}$. Plugs were assumed to occur at midnight so noon on the day of a plug was defined as embryonic day 0.5 (E0.5).

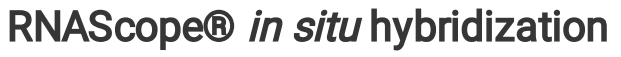


E15.5 and E17.5 CD1 mouse heads were fixed directly in 4\% paraformaldehyde (PFA) in phosphate buffered saline (PBS) overnight at $4^{\circ} \mathrm{C}$. Embryo heads were stepped through 10,20 and $30 \%$ sucrose in PBS, and embedded in NEG50 (Richard-Allan Scientific). Coronal head sections through the cochlea and the $\mathrm{CN}$ were prepared at $20 \mu \mathrm{m}$. In situ hybridization was performed according to the protocols of the RNAscope ${ }^{\circledR} 2.5$ HD Duplex Assay, the RNAscope 2.5 HD Assay - RED, or the RNAScope ${ }^{\circledR}$ Multiplex Fluorescent V2 Assay (Advanced Cell Diagnostics). The signals were detected using a horseradish peroxidase (HRP)-based chromogenic assay (blue signal), an alkaline phosphatase (AP)-based chromogenic assay (red signal), or an HRP-based Opal fluorophore assay (green, red, and far-red) (Akoya Biosciences).

Probes used were ephrin-A1 (Cat No. 428621), ephrin-A2 (Cat No. 507481-C2), ephrin-A3 (Cat No. 473971), ephrin-A4 (Cat No. 487621-C2), ephrin-A5 (Cat No. 316641-C2), Mafb (Cat No. 438531-C2), Atoh1 (Cat No. 408791-C3), c-fos (Cat No. 316921), EphA4 (Cat No. 419081), and EphA7 (Cat No. 458661). A negative control probe (Escherichia coli DapB, Cat No. 310043) and a positive control probe (mouse Ppib, Cat No 313911) were also included in the procedure to ensure that the assay was performed properly. Because the NeuN staining was not possible after the target retrieval procedure, we used DAPI (62248, Thermo Fisher Scientific) or a rabbit anti-TuJ1 antibody (802001, BioLegend) to counterstain the tissues to reveal the cellular structure or to mark the embryonic CN or the SGNs at the end of the in situ hybridization protocol. Tissue sections were blocked for one hour at room temperature in phosphate-buffered saline (PBS) containing $5 \%$ normal goat serum and $0.3 \%$ Triton X-100. Sections were then stained with the rabbit anti-TuJ1 antibody diluted in the blocking solution overnight at $4^{\circ} \mathrm{C}$, followed by Alexa Fluor-conjugated secondary antibodies (Thermo Fisher Scientific) at RT for one hour, and mounted in Fluoromount-G (0100-01, Southern Biotech). Images were acquired on a Nikon Eclipse NiU microscope using a Plan Apo $\lambda$ 4X (NA:0.2) or a Plan Fluor 10X (NA:0.3) objective, or on an Olympus FluoView FV1000 using a 100X (NA:1.40) oil-immersion objective.

\section{Ephrin-a3 Stripe Assay}

Stripe assays were conducted as described previously ${ }^{30}$. Briefly, 22-mm coverslips were first coated with poly-D-lysine (P7280, MilliporeSigma) at $0.1 \mathrm{mg} / \mathrm{ml}$ for 2 hours at $37^{\circ} \mathrm{C}$, rinsed twice with deionized water, sterilized with $70 \%$ ethanol, and air-dried. For experimental coverglasses, first stripe solutions contained 2-40 $\mathrm{gg} / \mathrm{ml}$ recombinant ephrin-A3-Fc chimera protein (359-EA-200, R\&D Systems) (human IgG-Fc were added together with $2-20 \mu \mathrm{g} / \mathrm{ml}$ ephrin-A3-Fc to fill in the concentration to $40 \mu \mathrm{g} / \mathrm{ml}$ ). For control coverglasses, first stripe solutions contained $40 \mu \mathrm{g} / \mathrm{ml}$ human IgG-Fc (AG714, MilliporeSigma). The chimera proteins or lgG-Fc were pre-clustered for $30 \mathrm{~min}$ on ice with $5 \mu \mathrm{g} / \mathrm{ml}$ Alexa Fluor 488 goat antihuman antibody in Hanks' balance salt solution (HBSS, Thermo Fisher Scientific). For the second stripe solution, $40 \mu \mathrm{g} / \mathrm{ml}$ human IgG-Fc was pre-clustered as above but with $5 \mu \mathrm{g} / \mathrm{ml}$ unconjugated goat antihuman Fc (AP113, MilliporeSigma). Silicon manifolds with 90- $\mu$ m channels purchased from Dr. Martin Bastmeyer ${ }^{31}$ were applied to polylysine-treated coverglasses. $100 \mu \mathrm{l}$ of the first stripe solution was put into the matrices and incubated for $30 \mathrm{~min}$ at $37^{\circ} \mathrm{C}$. After washing three times with HBSS, the matrices were removed and $100 \mu \mathrm{l}$ of the second stripe solution was applied and incubated for $30 \mathrm{~min}$ at $37^{\circ} \mathrm{C}$ to 
coat the unbound region between the first stripes. After three more washes with HBSS, the coverslips were incubated overnight at $4^{\circ} \mathrm{C}$ in $100 \mu$ of HBSS containing $2.5 \mu \mathrm{g} / \mathrm{ml}$ laminin (354232, BD Biosciences), followed by three washes with HBSS.

E15.5 or E17.5 CD1 cochleae were dissected out under sterile conditions. Cochlear explants were prepared by using a one-third turn of the cochlea from either the most basal aspect or the most apical aspect of the cochlea (cochleae from these stages contain about two full turns). Explants were plated on the coverslips in $100 \mu \mathrm{l}$ serum-free Neurobasal medium (21103049) containing $1.4 \mathrm{mM}$ L-glutamine (25030149), N2 supplement (17502048, all from Thermo Fisher Scientific), 10 ng/ml BDNF (CYT-207, ProSpec), and $10 \mathrm{ng} / \mathrm{ml} \mathrm{NT-3}$ (CYT-688, ProSpec), and cultured for $36-48$ hours at $37^{\circ} \mathrm{C}$ with $5 \% \mathrm{CO}_{2}$.

For staining, explant cultures were fixed with 4\% PFA in 0.1M sodium cacodylate, $\mathrm{pH} 7.4$ (11650, Electron Microscopy Sciences) containing $10 \mathrm{mM} \mathrm{MgCl}_{2}$ and $5 \mathrm{mM} \mathrm{CaCl}_{2}$ for $12 \mathrm{~min}$ and washed with $0.1 \mathrm{M}$ cacodylate buffer followed by PBS.

Explants were blocked for one hour at room temperature in PBS containing 1\% tween-20, 5\% DMSO, 1\% fish gelatin, and $1.4 \mathrm{mg} / \mathrm{ml} \mathrm{BSA} \mathrm{(PBSTD,} \mathrm{all} \mathrm{from} \mathrm{MilliporeSigma),} \mathrm{followed} \mathrm{by} \mathrm{a} \mathrm{1-hour} \mathrm{incubation} \mathrm{in}$ mouse anti-neurofilament (2H3, Developmental Studies Hybridoma Bank), mouse anti-GAP43 (MAB347, MilliporeSigma), and rabbit anti-Myosin-VI (25-6791, Proteus BioSciences).

Explants were washed three times in PBSTD, incubated in Alexa Fluor-conjugated secondary antibodies at RT for 40 min, washed three times again in PBSTD, and mounted in Fluoromount-G. Confocal images were obtained on an Olympus FluoView FV1000 using a XL Fluor 4X/340 (NA:0.28) or a 10X (NA:0.40) objective, or a $60 \mathrm{X}$ (NA:1.40) oil-immersion objective. A $1600 \times 1600$ image was acquired at the optimal step size (automatically calculated by the Olympus software) in the $Z$ axis.

For quantitative evaluation of ephrin-A3 repulsion, stripes were oriented vertically, and outgrowth of ANFs was divided into quadrants. We measured the longest ANF outgrowth that was continuous in the labeled stripes (stripes containing $0-40 \mu \mathrm{g} / \mathrm{ml}$ ephrin-A3-Fc) within the upper and lower quadrants (i.e., approximately parallel to the stripes) for each explant, and took the ratio of that value to the length of the longest ANFs in the unlabeled stripe (stripes containing no ephrin-A3-Fc) for the same explant. Multiple ANFs were considered in each stripe and the most common length of the longest 3-5 ANFs were used. ANFs that crossed over into different stripes were disregarded. Statistical significance between test groups was assessed by two-way ANOVA with post-hoc Welch's unequal variances t-test.

\section{Neurovue Labeling From The Cochlea To The AVCN}

E18.5 mouse heads were fixed directly in 4\% PFA in PBS overnight at $4^{\circ} \mathrm{C}$ and rinsed in PBS. The tissues on the ventral side of the head were removed to expose the cochlea. The cochlea was further dissected to reveal the basal and apical turns. NeuroVue labeling was performed as described previously ${ }^{19}$. Small incisions were created using a Dumont \#5 super fine forceps (11252-00, Fine Science Tools) at a location between the middle and basal turns and at the apical turn. Special care was taken to make sure that the incisions were made around the same position of the cochlea between each sample. Paper strips coated 
with distinct NeuroVue ${ }^{\circledR}$ dyes (Red FS-1002 or Maroon FS-1001, Molecular Targeting Technologies) were inserted into the incisions at the different turns of the cochlea. The heads were incubated in 4\% PFA in PBS at $37^{\circ} \mathrm{C}$ for 10 days. The brain was dissected out and embedded in $4 \%$ low melting agarose (IB70056, IBI Scientific) in PBS. $60 \mu \mathrm{m}$ vibratome sections anterior to the eighth nerve root were identified as the AVCN and collected. The dissected cochlea and AVCN sections were counterstained with an antiNeuN antibody (ab177487, Abcam) and mounted in Fluoromount-G. Confocal images were obtained on an Olympus FluoView FV1000 using a 4X/340 (NA:0.28, for the cochlea) or a 10X (NA:0.40, for the AVCN) objective at the optimal Z-step size. ImageJ (National Institutes of Health) was used to calculate areas in the AVCN and to measure the angular spread of the NeuroVue dye in the cochlea. $\theta_{\mathrm{mb}}$ or $\theta_{\mathrm{a}}$ is the angular spread of the dye in the mid-basal or apical cochlear turn. $S_{m b}$ or $S_{a}$ is the AVCN area innervated by NeuroVue-labeled ANFs from the mid-basal or the apical cochlear turn. $S_{A V C N}$ is the total AVCN area. For measurement of the $\theta_{\mathrm{mb}}$ or $\theta_{\mathrm{a}}$, the origin of the angular spread was determined as the point where dye labeled ANFs are converging on the auditory nerve. The boundaries of the angular spread were demarcated by the sector containing dye labeled SGNs. For measurement of $S_{m b}, S_{a}$, and $S_{A V C N}$, the section containing the largest $S_{A V C N}$ was chosen for analysis in each animal. The AVCN border was demarcated from the small granule cell region according to the NeuN staining. The fraction of AVCN area innervated by dye labeled ANFs from the mid-basal or apical turn were calculated as $\left(S_{\mathrm{mb}} / \mathrm{S}_{\mathrm{AVCN}} \times 100\right)$ or $\left(\mathrm{S}_{\mathrm{a}} / \mathrm{S}_{\mathrm{AVCN}} \times 100\right)$ respectively and normalized to $\theta_{\mathrm{mb}}$ or $\theta_{\mathrm{a}}$. The values obtained from the control and Ephrin- $A 3^{-/-}$mutant mice were then compared using the Welch's t-test.

\section{$c$-fos induction assay after pure tone stimulation}

c-fos activation after pure tone stimulation was performed as described previously ${ }^{19,26}$. Freely moving 5 7-week-old mice were placed inside a custom-made cylinder enclosure (14 cm diameter $\times 15 \mathrm{~cm}$ height) built using stainless steel wire mesh. The mice in the enclosure were kept in silence in an anechoic chamber (ENV-022SD, Med Associates) for an hour, followed by exposure to free field tone pips (16 kHz and/or $8 \mathrm{KHz}$ ) at $75 \mathrm{~dB}$ sound pressure level (SPL) for $90 \mathrm{~min}$. Tones were delivered using a RZ6 Multi-I/O processor (Tucker-Davis Technologies) with a Crown DCi 2|300 power amplifier and a Pyramid TW57 speaker. The speaker was mounted on the top of the cylinder enclosure and positioned approximately 10 $\mathrm{cm}$ above the mouse head. Stimuli were calibrated using a $1 / 4$ inch free-field microphone (378C01, PCB Piezotronics). One group of animals were exposed to $16 \mathrm{kHz}$ tone pips (400 ms duration, with a $5 \mathrm{~ms}$ risefall time and $300 \mathrm{~ms}$ gap, presented at $1.43 \mathrm{~Hz}$ frequency) for $90 \mathrm{~min}$. One group of animals were exposed to $8 \mathrm{kHz}$ tone pips (50 ms duration, with a $4 \mathrm{~ms}$ rise-fall time and $40 \mathrm{~ms}$ gap, presented at 11.1 $\mathrm{Hz}$ frequency) for $90 \mathrm{~min}$. The third group of animals were exposed to alternating $8 \mathrm{kHz}$ (400 ms, 1.43 $\mathrm{Hz})$ and $16 \mathrm{kHz}(400 \mathrm{~ms}, 1.43 \mathrm{~Hz})$ dual tones for $90 \mathrm{~min}$. The acoustic stimuli were composed using the RPvdsEx software (Tucker-Davis Technologies).

Immediately after tone exposure, animals were transcardially perfused with ice-cold PBS, followed by $4 \%$ PFA in PBS. 
Brains were post-fixed in $4 \%$ PFA in PBS for 24 hours at $4^{\circ} \mathrm{C}$, stepped through the sucrose gradient and embedded as described above, and coronal brain sections through the AVCN were prepared at $40 \mu \mathrm{m}$. In a previous study, the authors found that the Calbiochem P38 c-fos antibody could label c-fos-positive activated cells in the AVCN, but no other c-fos antibodies could label activated cells in the AVCN ${ }^{19}$. Because the P38 c-fos antibody was discontinued, we tried three other c-fos antibodies (Novus Biologicals NB2-50037 and NBP1-89065, and Abcam Ab190089) for immunostaining. Indeed, although all three c-fos antibodies can label c-fos-activated cells in other brain regions and in the DCN, none could detect activated cells in the AVCN. Therefore, we used in situ hybridization to detect c-fos activation. In situ hybridization of $c$-fos was performed using RNAscope 2.5 HD Assay - RED as described above.

For quantification, the area covered by the c-fos-positive cells or the separation area between two activated isofrequency bands upon dual-tone exposure, and the total AVCN area were measured using the ImageJ. The section containing the largest AVCN area was chosen for analysis in each animal. The AVCN border was demarcated from the small granule cell region based on the DAPI staining. The percentage of c-fos-positive area in the AVCN or the percentage of the area between the two c-fos-positive bands in the AVCN was calculated and compared between the control and ephrin- $A 3^{-/-}$mutant animals using the Welch's t-test.

\section{Auditory Brainstem Response (ABR) Recordings}

5-7-week-old mice were anesthetized with ketamine (1 mg/10 body weight IP injection, 07-893-5790, Patterson Veterinary) and xylazine (0.1 mg/10g body weight IP injection, 07-891-9200, Patterson Veterinary). Needle electrodes (ELE-N, Tucker-Davis Technologies) were inserted subdermally at the vertex of the skull (recording electrode), the lower region below the stimulated ear (reference electrode), and the hind hip of the animal (ground electrode). ABR recordings were conducted inside the Med Associates anechoic chamber using an open field setup. A MF1 Multi Field Magnetic speaker (Tucker-Davis Technologies) was placed $10 \mathrm{~cm}$ from the subject's ear and positioned in line with the axis of the ear canal. Stimulation protocols of tone bursts were programmed in the SigGenRZ software and presented using the BioSigRZ software (both from Tucker-Davis Technologies). ABR recordings were conducted using tone pips at $5.6,8,11.3,16,22.6,32,45.2 \mathrm{kHz}(4.5 \mathrm{~ms}$ in duration with a $0.4 \mathrm{~ms}$ rise/fall time presented at a rate of $40 \mathrm{~Hz}$ ) in $5 \mathrm{~dB}$ steps from below threshold to $90 \mathrm{~dB}$ SPL as described previously 32 . The voltage difference between the recording and the reference electrodes was amplified, filtered, digitized, and averaged across 512 presentations in the BioSigRZ. Wave amplitudes and latencies of ABRs were extracted from the BioSigRZ. Threshold was defined by visual inspection of stacked waveforms. Statistical significance was analyzed using Welch's unequal variances t-test.

\section{Acoustic Startle Response (ASR)-based Assays For Evaluating Frequency Discrimination}

ASR-based procedures of assessing frequency discrimination in mice were conducted as described previously ${ }^{33-35}$ using a semi-custom-made setup. The audio files were programmed using the Audacity software and saved as waveform audio (WAV) files. Auditory stimulation was delivered through an ADI-2 
Pro FS AD/DA Converter (RME Audio) with a Crown DCi 2/600 amplifier and a TL16H super tweeter speaker (200W peak, frequency response: $2.2 \mathrm{kHz} \sim 35 \mathrm{kHz}$, VISATON). The TL16H tweeter was used because it has a very flat response from 5 to $20 \mathrm{kHz}$ and a uniformly distributed energy pattern. Auditory stimuli were calibrated by the REW acoustics analysis software using the PCB 378C01 1/4 inch free-field microphone placed at the level of the subject's ear within an animal holder (ENV-263A, Med Associates) in the anechoic chamber. Animals were habituated for four days prior to the test. On the first day, the animal holder was placed inside each mouse cage. On the second day, each animal was placed in the holder for $25 \mathrm{~min}$ inside the anechoic chamber. On the third and fourth days, a $16 \mathrm{kHz}$ background tone at $70 \mathrm{~dB}$ SPL was presented to the animal for $25 \mathrm{~min}$ from the TL16H tweeter placed $10 \mathrm{~cm}$ in front of the animal. At the beginning of the assay, animals in the holder were allowed to acclimate to the $16 \mathrm{kHz}$ background tone (F1 tone) at $70 \mathrm{~dB}$ SPL for five min, followed by startle-only and prepulse trials. The sequences of the trials were composed using the Advanced Startle software (SOF-828, Med Associates) and contained three parts. The first part consisted of a series of startle-only trials for short-term habituation. The second part comprised prepulse trials randomly mixed with an equal number of startleonly trials. 7 prepulse frequencies (F2 tones) used were $15.92 \mathrm{kHz}(0.5 \%$ change), $15.68 \mathrm{kHz}$ ( $2 \%$ change), $15.47 \mathrm{kHz}$ (3.3\% change), $15.2 \mathrm{kHz}$ (5\% change), $14.4 \mathrm{kHz}$ (10\% change), $13.34 \mathrm{kHz}$ (16.6\% change), and $12 \mathrm{kHz}$ (25\% change). The third part was made up of a serial of startle-only trials again to assess habituation during the course of the assay. In prepulse trials, the prepulse stimulus contained a frequency change of a linear rise-fall of $1 \mathrm{~ms}$ from the background F1 tone to the prepulse F2 tone at $70 \mathrm{~dB}$ SPL. F2 tone was maintained for $80 \mathrm{~ms}$ in the inter-stimulus interval (ISI), followed by the startle stimulus of a white noise burst at $120 \mathrm{~dB}$ SPL for $40 \mathrm{~ms}$ (Fig. 7a-e). After the startle stimulus, F1 background tone was given again until the prepulse stimulus of the next trial. For startle only trials, the prepulse stimulus comprised a linear rise-fall of $1 \mathrm{~ms}$ from F1 tone to F1 tone without actually introducing a frequency change. All trials were separated randomly by an interval range from 10-20 s. The vertical force exerted by the animal was recorded on a platform load cell assembly with an amplifier (PHM-255A and PHM250B, Med Associates) and acquired and digitized by a PCI Data Acquisition Card and an A/D interface (DIG-744 and ANL-729, Med Associates) using the Advanced Startle software. All mice were monitored during the assay by a USB infrared webcam (ELPUSBFHD01M, Ailipu Technology). Two 500-ms periods were recorded in each trial (Fig. 7a). The baseline activity was recorded in the first 500-ms period, which happened immediately before the prepulse. The ASR was recorded in the second 500-ms period, which started at the onset of the startle stimulus. Both the positive and negative directions of the maximum force were recorded and reported as the ASR. The recording traces were exported and analyzed in the Microsoft Excel. Statistical significance was assessed using two-way ANOVA with post-hoc Welch's t-test.

\section{Statistics}

All statistical analyses were carried out in Microsoft Excel and GraphPad Prism to determine if sets of data are significantly different from each other. The difference between means was considered significant if $p<0.05$. Data were plotted using GraphPad Prism. The results are expressed as means \pm SDs unless otherwise noted. 


\section{Declarations}

\section{Acknowledgements}

This work was supported by the National Institutes of Health (R15DC016407 to M.W.R. and R15DC017866 to W.Y.).

\section{Author contributions}

N.H., V.C.C., M.W.R., and W.Y. conceived of and designed the study. N.H., Y.A., A.A., A.M.F., M.W.R., and W.Y. performed the experiments and collect the data. N.H., Y.A., H.T.N., E.F.M., and W.Y. analyzed the data and conducted statistical analysis. W.Y. wrote the manuscript.

\section{Competing interests}

The authors declare no competing interests.

\section{References}

1 Kandler, K., Clause, A. \& Noh, J. Tonotopic reorganization of developing auditory brainstem circuits. Nature neuroscience 12, 711-717 (2009).

2 Yu, W. M. \& Goodrich, L. V. Morphological and physiological development of auditory synapses. Hear Res 311, 3-16, doi:10.1016/j.heares.2014.01.007 (2014).

3 Fekete, D. M., Rouiller, E. M., Liberman, M. C. \& Ryugo, D. K. The central projections of intracellularly labeled auditory nerve fibers in cats. J Comp Neuro/ 229, 432-450, doi:10.1002/cne.902290311 (1984).

4 Muniak, M. A. et al. 3D model of frequency representation in the cochlear nucleus of the CBA/J mouse. J Comp Neuro/ 521, 1510-1532, doi:10.1002/cne.23238 (2013).

5 Scheffel, J. L. et al. Spatiotemporal Analysis of Cochlear Nucleus Innervation by Spiral Ganglion Neurons that Serve Distinct Regions of the Cochlea. Neuroscience 446, 43-58 (2020).

6 Koundakjian, E. J., Appler, J. L. \& Goodrich, L. V. Auditory neurons make stereotyped wiring decisions before maturation of their targets. J Neurosci 27, 14078-14088, doi:10.1523/JNEUROSCI.376507.2007 (2007).

7 Matei, V. et al. Smaller inner ear sensory epithelia in Neurog 1 null mice are related to earlier hair cell cycle exit. Dev Dyn 234, 633-650, doi:10.1002/dvdy.20551 (2005).

8 Ruben, R. J. Development of the inner ear of the mouse: a radioautographic study of terminal mitoses. Acta Otolaryngol, Suppl 220:221-244 (1967). 
9 Shepard, A. R., Scheffel, J. L. \& Yu, W. M. Relationships between neuronal birthdates and tonotopic positions in the mouse cochlear nucleus. J Comp Neuro/ 527, 999-1011, doi:10.1002/cne.24575 (2019).

10 Pierce, E. T. Histogenesis of the dorsal and ventral cochlear nuclei in the mouse. An autoradiographic study. J Comp Neuro/ 131, 27-54, doi:10.1002/cne.901310104 (1967).

11 Martin, M. R. \& Rickets, C. Histogenesis of the cochlear nucleus of the mouse. J Comp Neuro/ 197, 169-184, doi:10.1002/cne.901970113 (1981).

12 Jhaveri, S. \& Morest, D. K. Sequential alterations of neuronal architecture in nucleus magnocellularis of the developing chicken: a Golgi study. Neuroscience 7, 837-853, doi:10.1016/03064522(82)90046-x (1982).

13 Clause, A. et al. The precise temporal pattern of prehearing spontaneous activity is necessary for tonotopic map refinement. Neuron 82, 822-835, doi:10.1016/j.neuron.2014.04.001 (2014).

14 Leake, P. A., Snyder, R. L. \& Hradek, G. T. Postnatal refinement of auditory nerve projections to the cochlear nucleus in cats. J Comp Neuro/ 448, 6-27, doi:10.1002/cne.10176 (2002).

15 Jackson, H. \& Parks, T. N. Functional synapse elimination in the developing avian cochlear nucleus with simultaneous reduction in cochlear nerve axon branching. $J$ Neurosci 2, 1736-1743 (1982).

16 Yang, T., Kersigo, J., Wu, S., Fritzsch, B. \& Bassuk, A. G. Prickle1 regulates neurite outgrowth of apical spiral ganglion neurons but not hair cell polarity in the murine cochlea. PLoS One 12, e0183773, doi:10.1371/journal.pone.0183773 (2017).

17 Macova, I. et al. Neurod1 Is Essential for the Primary Tonotopic Organization and Related Auditory Information Processing in the Midbrain. J Neurosci 39, 984-1004, doi:10.1523/JNEUROSCI.2557-18.2018 (2019).

18 Lu, C. C. et al. Mutation of Npr2 leads to blurred tonotopic organization of central auditory circuits in mice. PLoS Genet 10, e1004823, doi:10.1371/journal.pgen.1004823 (2014).

19 Karmakar, K. et al. Hox2 Genes Are Required for Tonotopic Map Precision and Sound Discrimination in the Mouse Auditory Brainstem. Cell Rep 18, 185-197, doi:10.1016/j.celrep.2016.12.021 (2017).

20 Kania, A. \& Klein, R. Mechanisms of ephrin-Eph signalling in development, physiology and disease. Nat Rev Mol Cell Biol 17, 240-256, doi:10.1038/nrm.2015.16 (2016).

21 Cramer, K. S. \& Miko, I. J. Eph-ephrin signaling in nervous system development. F1000Res 5, doi:10.12688/f1000research.7417.1 (2016). 
22 Egea, J. \& Klein, R. Bidirectional Eph-ephrin signaling during axon guidance. Trends Cell Bio/ 17, 230-238, doi:10.1016/j.tcb.2007.03.004 (2007).

23 Triplett, J. W. \& Feldheim, D. A. Eph and ephrin signaling in the formation of topographic maps. Semin Cell Dev Biol 23, 7-15, doi:10.1016/j.semcdb.2011.10.026 (2012).

24 Siddiqui, S. A. \& Cramer, K. S. Differential expression of Eph receptors and ephrins in the cochlear ganglion and eighth cranial nerve of the chick embryo. J Comp Neuro/ 482, 309-319, doi:10.1002/cne.20396 (2005).

25 Huffman, K. J. \& Cramer, K. S. EphA4 misexpression alters tonotopic projections in the auditory brainstem. Dev Neurobio/ 67, 1655-1668, doi:10.1002/dneu.20535 (2007).

26 Miko, I. J., Nakamura, P. A., Henkemeyer, M. \& Cramer, K. S. Auditory brainstem neural activation patterns are altered in EphA4- and ephrin-B2-deficient mice. J Comp Neuro/ 505, 669-681, doi:10.1002/cne.21530 (2007).

27 Miko, I. J., Henkemeyer, M. \& Cramer, K. S. Auditory brainstem responses are impaired in EphA4 and ephrin-B2 deficient mice. Hear Res 235, 39-46, doi:10.1016/j.heares.2007.09.003 (2008).

28 Cramer, K. S. \& Gabriele, M. L. Axon guidance in the auditory system: multiple functions of Eph receptors. Neuroscience 277, 152-162, doi:10.1016/j.neuroscience.2014.06.068 (2014).

29 Carmona, M. A., Murai, K. K., Wang, L., Roberts, A. J. \& Pasquale, E. B. Glial ephrin-A3 regulates hippocampal dendritic spine morphology and glutamate transport. Proc Natl Acad Sci U S A 106, 1252412529, doi:10.1073/pnas.0903328106 (2009).

30 Treffy, R. W. et al. Ephrin-B/EphB Signaling Is Required for Normal Innervation of Lingual Gustatory Papillae. Dev Neurosci 38, 124-138, doi:10.1159/000444748 (2016).

31 Knöll, B., Weinl, C., Nordheim, A. \& Bonhoeffer, F. Stripe assay to examine axonal guidance and cell migration. Nat Protoc 2, 1216-1224, doi:10.1038/nprot.2007.157 (2007).

$32 \mathrm{Yu}, \mathrm{W}$. M. et al. A Gata3-Mafb transcriptional network directs post-synaptic differentiation in synapses specialized for hearing. Elife 2, e01341, doi:10.7554/eLife.01341 (2013).

33 Clause, A., Nguyen, T. \& Kandler, K. An acoustic startle-based method of assessing frequency discrimination in mice. J Neurosci Methods 200, 63-67, doi:10.1016/j.jneumeth.2011.05.027 (2011).

34 Mwilambwe-Tshilobo, L., Davis, A. J., Aizenberg, M. \& Geffen, M. N. Selective Impairment in Frequency Discrimination in a Mouse Model of Tinnitus. PLoS One 10, e0137749, doi:10.1371/journal.pone.0137749 (2015). 
35 Clause, A., Lauer, A. M. \& Kandler, K. Mice Lacking the Alpha9 Subunit of the Nicotinic Acetylcholine Receptor Exhibit Deficits in Frequency Difference Limens and Sound Localization. Front Cell Neurosci 11, 167, doi:10.3389/fncel.2017.00167 (2017).

36 Fujiyama, T. et al. Inhibitory and excitatory subtypes of cochlear nucleus neurons are defined by distinct bHLH transcription factors, Ptf1a and Atoh1. Development 136, 2049-2058, doi:10.1242/dev.033480 (2009).

37 Saul, S. M. et al. Math5 expression and function in the central auditory system. Mol Cell Neurosci 37, 153-169, doi:10.1016/j.mcn.2007.09.006 (2008).

38 Feldheim, D. A. et al. Genetic analysis of ephrin-A2 and ephrin-A5 shows their requirement in multiple aspects of retinocollicular mapping. Neuron 25, 563-574, doi:10.1016/s0896-6273(00)81060-0 (2000).

39 Melcher, J. R., Guinan, J. J., Knudson, I. M. \& Kiang, N. Y. Generators of the brainstem auditory evoked potential in cat. II. Correlating lesion sites with waveform changes. Hear Res 93, 28-51, doi:10.1016/0378-5955(95)00179-4 (1996).

40 Coate, T. M. et al. Otic mesenchyme cells regulate spiral ganglion axon fasciculation through a Pou3f4/EphA4 signaling pathway. Neuron 73, 49-63, doi:10.1016/j.neuron.2011.10.029 (2012).

$41 \mathrm{Kim}, \mathrm{Y}$. J. et al. EphA7 regulates spiral ganglion innervation of cochlear hair cells. Dev Neurobiol 76, 452-469, doi:10.1002/dneu.22326 (2016).

42 Defourny, J. Eph/ephrin signalling in the development and function of the mammalian cochlea. Dev Bio/ 449, 35-40, doi:10.1016/j.ydbio.2019.02.004 (2019).

43 Yoo, S. et al. Endocytosis of EphA receptors is essential for the proper development of the retinocollicular topographic map. EMBO J 30, 1593-1607, doi:10.1038/emboj.2011.44 (2011).

44 Shintani, T. et al. Eph receptors are negatively controlled by protein tyrosine phosphatase receptor type O. Nat Neurosci 9, 761-769, doi:10.1038/nn1697 (2006).

45 Schmucker, D. \& Zipursky, S. L. Signaling downstream of Eph receptors and ephrin ligands. Cell 105, 701-704, doi:10.1016/s0092-8674(01)00391-9 (2001).

46 Schmitt, A. M. et al. Wnt-Ryk signalling mediates medial-lateral retinotectal topographic mapping. Nature 439, 31-37, doi:10.1038/nature04334 (2006).

47 Batlle, E. et al. Beta-catenin and TCF mediate cell positioning in the intestinal epithelium by controlling the expression of EphB/ephrinB. Cell 111, 251-263, doi:10.1016/s0092-8674(02)01015-2 (2002). 
48 Chermak, G. D., Musiek, F. E. \& Craig, C. H. Central Auditory Processing Disorders: New Perspectives. (Singular Pub Group, 1997).

\section{Figures}

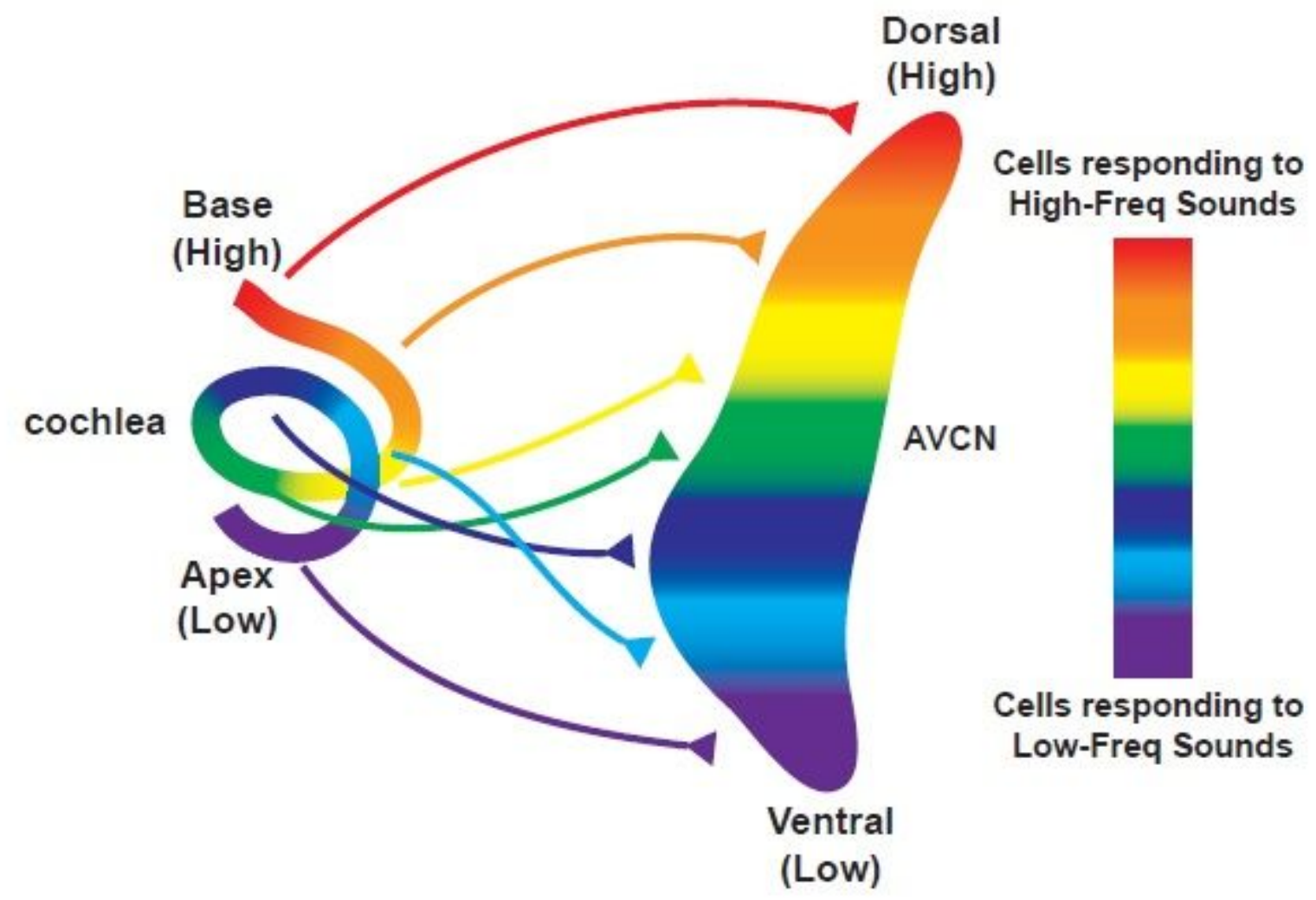

\section{Figure 1}

Schematic drawing of tonotopic connectivity between the cochlea and the cochlear nucleus (CN). Only the anteroventral cochlear nucleus (AVCN) is shown. The posteroventral cochlear nucleus (PVCN) and dorsal cochlear nucleus (DCN) also follow a similar tonotopic connectivity. 

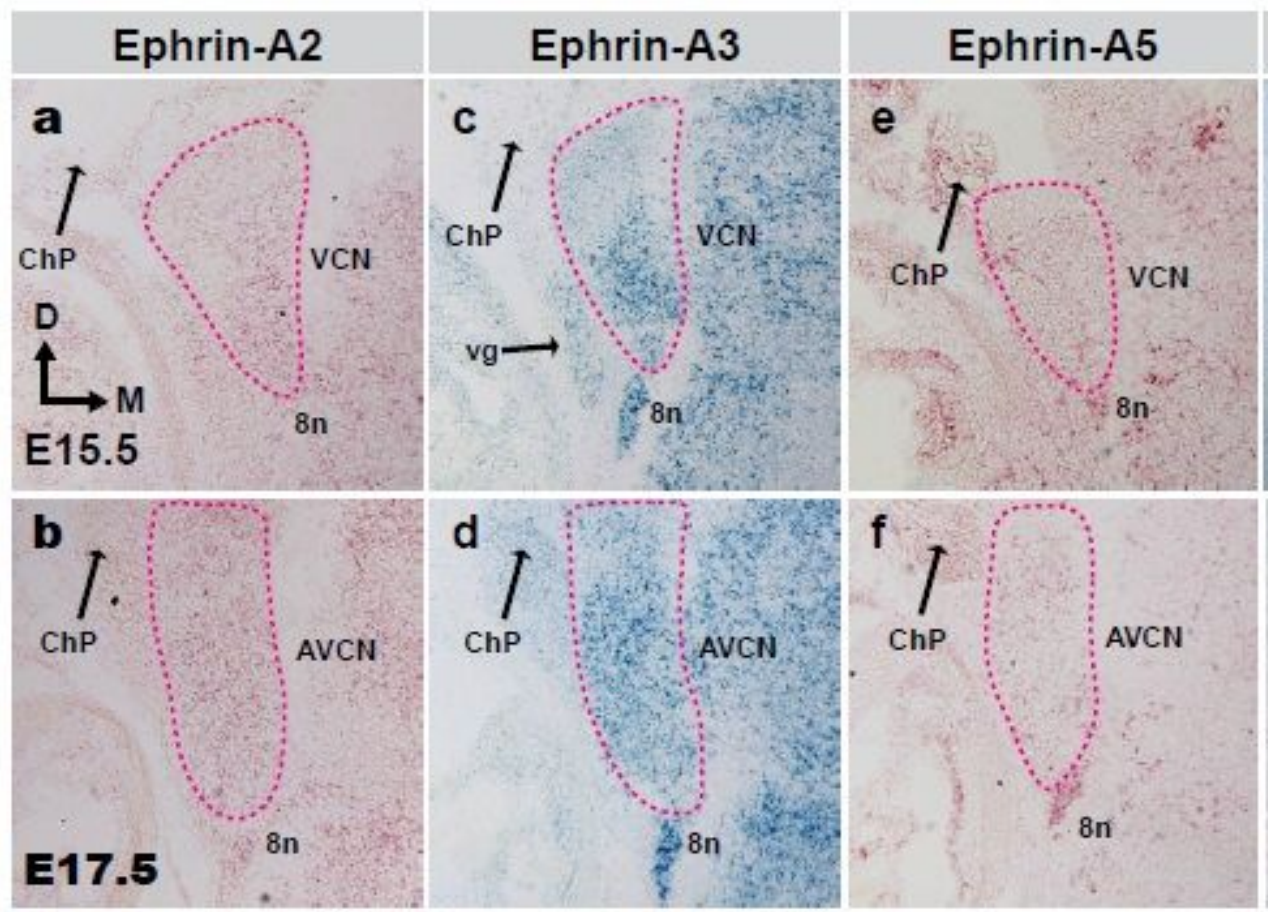

\section{A3 on Ephrin-A3 $3^{-1-}$}
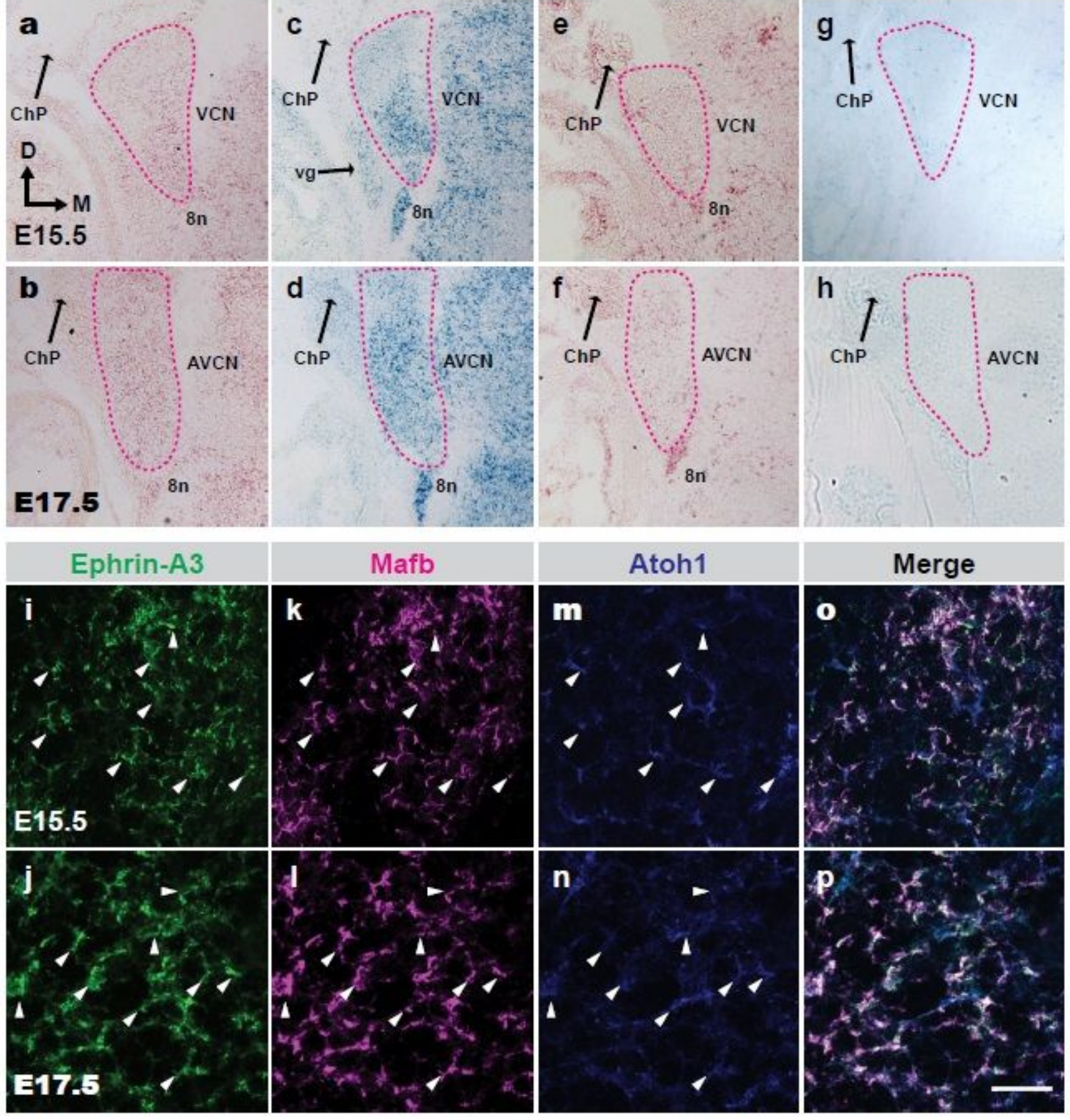

\section{Figure 2}

Expression of ephrin-As in the E15.5 or E17.5 mouse CN. a-f The expression levels of ephrin-As in the CN were detected by RNAScope ${ }^{\circledR}$ in situ hybridization using an HRP-based chromogen (blue) or an AP-based chromogen (red). Only VCN or AVCN are shown and outlined with magenta dashed lines. Ephrin-A1 and ephrin-A4 are not expressed inside the $\mathrm{CN}$ (not shown). Ephrin-A2 and -A5 are expressed at low levels in the developing VCN/AVCN. Ephrin-A3 is expressed in a ventral to dorsal descending gradient in the developing VCN/AVCN. $g$, h The specificity of ephrin-A3 probes was validated by a negative signal on sections from ephrin-A3-/- mice. ChP: Choroid plexus of the 4th ventricle; $8 \mathrm{n}$ : eighth nerve; vg: vestibular ganglion. The axis in (a) indicates the orientation of all the sections in the figure. D, dorsal; M, medial. i-p 
Expression of ephrin-A3, Mafb, and Atoh1 were detected by RNAScope® multiplex in situ hybridization in VCN cells using HRP-based Opal fluorophores [ephrin-A3: Opal 520 (green), Mafb: Opal 570 (pseudocolored magenta), and Atoh1: Opal 690 (pseudo-colored blue)]. Ephrin-A3 expression was found in cells

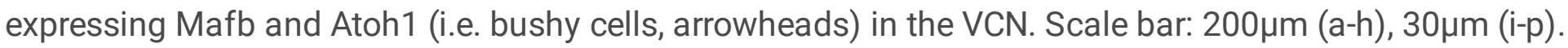
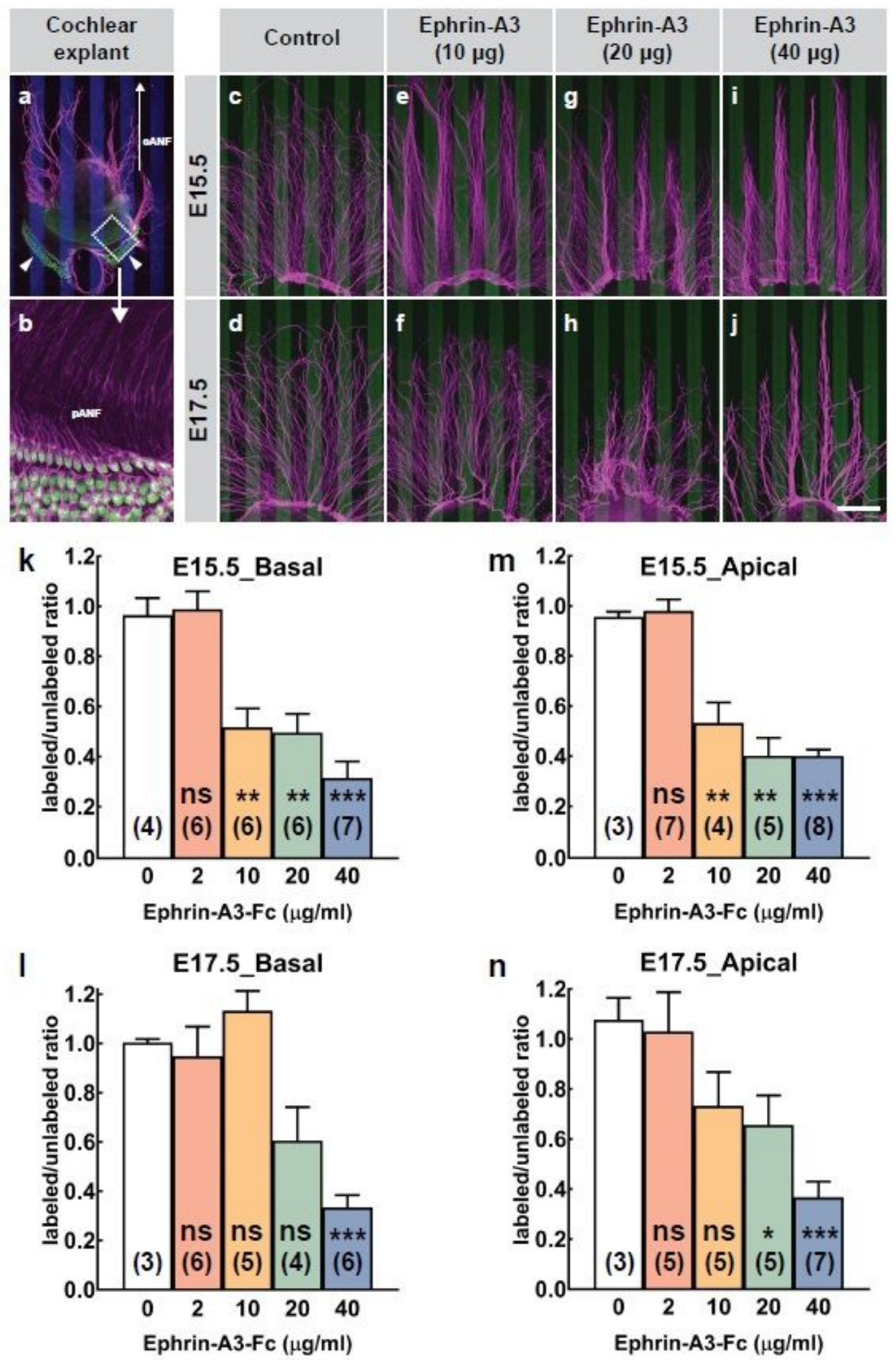

Figure 3 
Ephrin-A3 forward signaling repels central processes of auditory nerve fibers (ANFs) in a stage-dependent manner. a, b An explant from the E17.5 basal cochlear turn was cultured on the stripes containing preclustered ephrin-A3-Fc (40 $\mathrm{g} / \mathrm{ml}$, shown in pseudo-colored blue) for 36 hours, and stained with antiMyosin- 6 to mark the developing hair cells (green, arrowheads in a) and anti-neurofilament/GAP43 to reveal growing ANFs (magenta). (b) is the high magnification of the boxed region in (a). In this culture system, the peripheral processes of ANFs are still preserved but their staining intensity is much weaker than the intensity of the central processes. Peripheral processes can only be visualized at a magnification higher than 600X as shown in (b). This allows us to distinguish ANF central processes on the stripes from their peripheral processes. CANF or pANF: ANF central or peripheral processes. c-j Explants from E15.5 or E17.5 apical cochlear turns cultured on the stripes containing different concentrations of pre-clustered ephrin-A3-Fc. In control cultures, both stripes contained pre-clustered unconjugated human-IgG Fc $(40 \mu \mathrm{g} / \mathrm{ml})$ but the first stripe was pre-clustered with an Alexa-488-goat anti-human IgG-Fc (green stripes) whereas the second stripe was pre-clustered with an unlabeled goat anti-human IgG-Fc (uncolored stripes). In ephrin-A3 cultures, the first stripe contained 10, 20, or 40 $\mathrm{g} / \mathrm{ml}$ ephrin-A3-Fc pre-clustered with an Alexa-488-goat anti-human IgG-Fc (green stripes) and the second stripe (uncolored) was the same as in control cultures. No bias is observed in control cultures (c, d). ANFs show a developmentally reduced response to ephrin-A3. At E15.5, ANFs were already strongly repelled by stripes containing $10 \mu \mathrm{g} / \mathrm{ml}$ ephrin-A3-Fc (e, g, i). In contrast, E17.5 ANFs can only be repelled by stripes when ephrin-A3-Fc

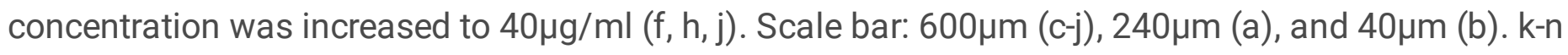
Statistics of stripe assays indicates that ANFs show a developmentally reduced sensitivity to ephrin-A3. At E15.5, both apical and basal ANFs were strongly repelled by $10 \mu \mathrm{g} / \mathrm{ml}$ ephrin-A3-Fc stripes. At E17.5, basal ANFs only showed repulsion to $40 \mu \mathrm{g} / \mathrm{ml}$ ephrin-A3-Fc stripes. Apical ANFs showed weak repulsion to $20 \mu \mathrm{g} / \mathrm{ml}$ ephrin-A3-Fc stripes and repulsion to $40 \mu \mathrm{g} / \mathrm{ml}$ ephrin-A3-Fc stripes. Numbers on the bar indicate the sample size. Means $\pm S D$ s are shown. ns: no significance, $*$ : $P<0.05, * *: P<0.01, * * *: P<0.001$, Two-way ANOVA with post-hoc Welch's t-test. 


\section{a}

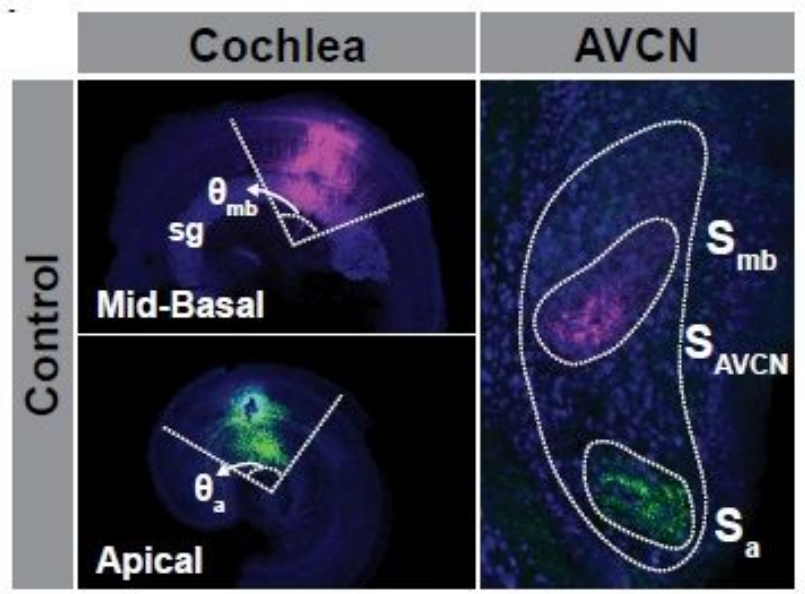

b

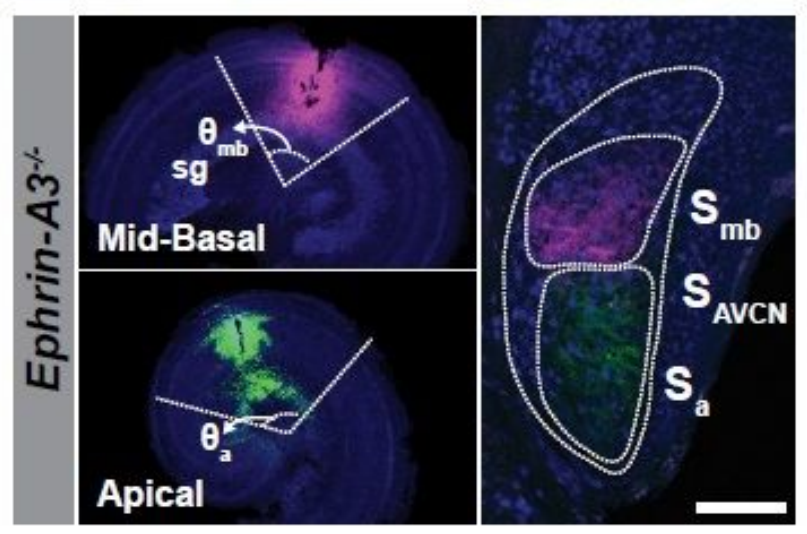

c

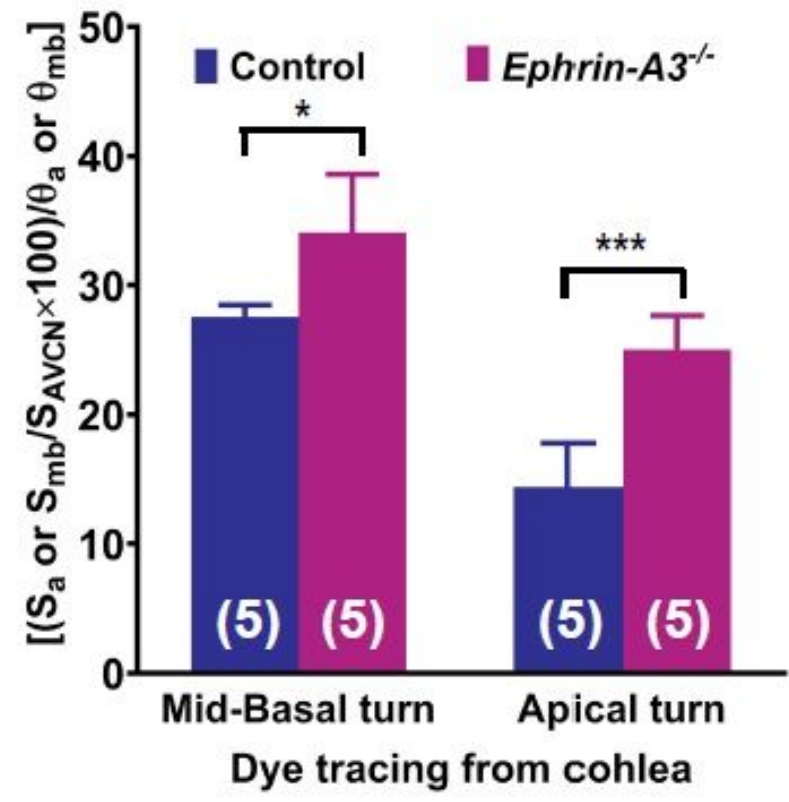

\section{Figure 4}

Reduced tonotopic precision of ANF inputs in ephrin-A3-/- mutant AVCN. a, b NeuroVue labeling of midbasal (magenta) and apical cochlear turns (green), and their NeuroVue tracing in the AVCN (magenta: terminals from mid-basal ANFs; green: terminals from apical ANFs) in E18.5 control and ephrin-A3-/mice. The cochlea and AVCN were counter-stained with anti-NeuN (blue) to reveal the cellular structure. The NeuroVue-labeled ANFs from mid-basal or apical cochlear turns target distinct regions along the 
tonotopic axis of the AVCN in both control and ephrin-A3-/- mice. However, the dye tracing from ephrinA3-/- ANFs in the AVCN was more spread out when compared to the tracing from control ANFs. sg: spiral ganglion; $\theta \mathrm{mb}$ or $\theta$ a: the angular spread of NeuroVue dyes in the mid-basal or apical cochlear turn; Smb or Sa: the AVCN area innervated by NeuroVue-labeled ANFs from mid-basal or apical cochlear turns; SAVCN: total AVCN area. Scale bar: $300 \mu \mathrm{m}$ for cochleae and $100 \mu \mathrm{m}$ for AVCN. c Welch's unequal variances t-test shows that ANFs innervate a significant larger area in ephrin-A3-/- AVCN than in control AVCN. Mid-basal ephrin-A3-/- ANFs target 24\% more area and apical ephrin-A3-/- ANFs target 70\% more area in the mutant AVCN when compared to the AVCN area targeted by control ANFs. Numbers on the bar indicate the sample size. Means \pm SDs are shown. *: $P<0.05, \star \star \star: P<0.001$. 


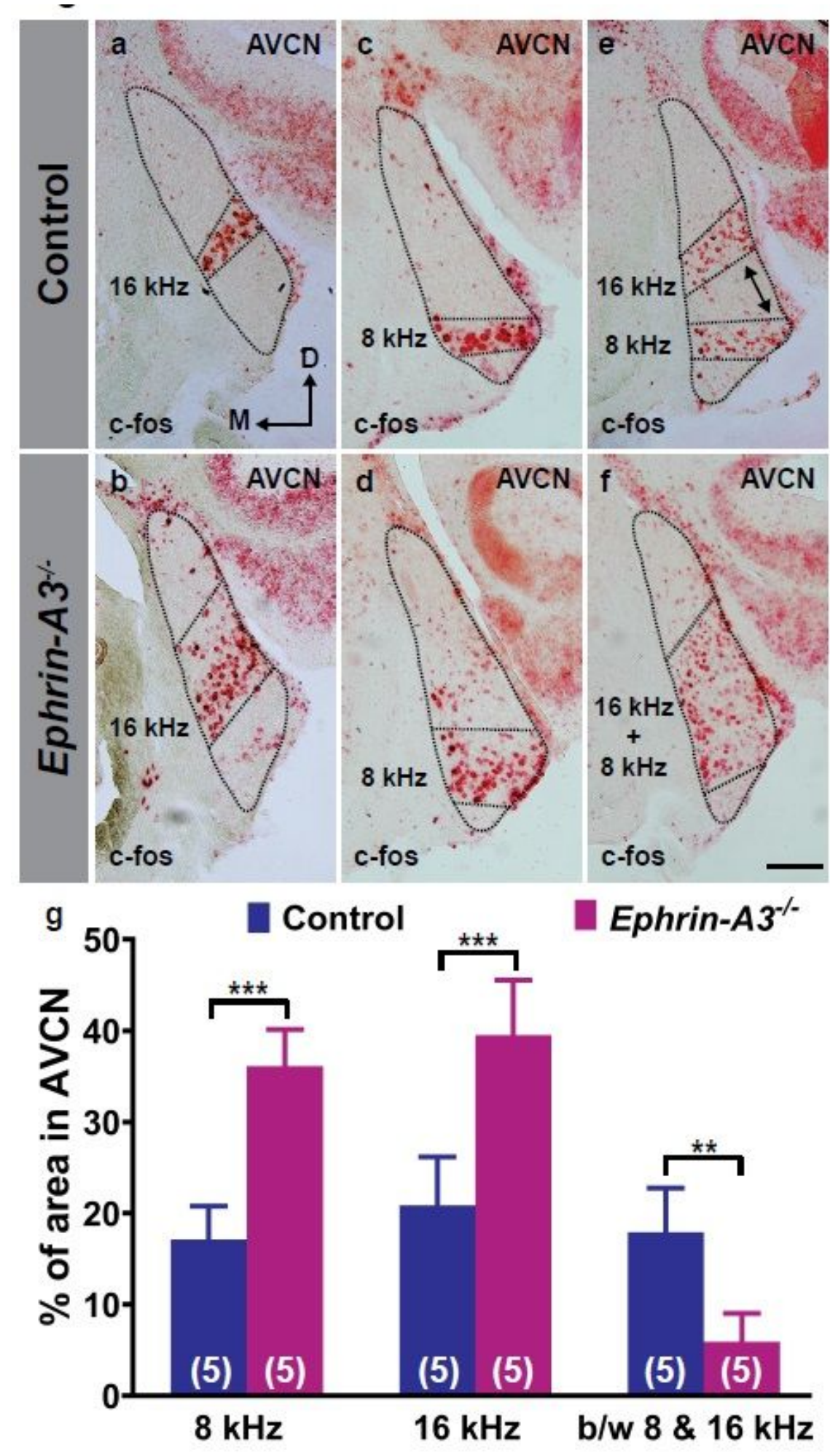

\section{Figure 5}

c-fos activation isofrequency bands are broadened in ephrin-A3-/- mutant AVCN upon pure tone stimulation. a-f c-fos-activated AVCN neurons detected by RNAScope ${ }^{\circledR}$ in situ hybridization in response to stimulation of a single $16-\mathrm{kHz}$ tone, a single $8 \mathrm{-kHz}$ tone, or simultaneous $16-$ and $8-\mathrm{kHz}$ dual tones in control and ephrin-A3-/- mutant AVCN. c-fos+ bands in AVCN after 16-kHz stimulation or 8-kHz stimulation are broader in ephrin-A3-/- mutants than in controls (a-d). Upon 16-kHz and 8-kHz dual tone 
exposure, a separation zone between the two c-fos-activated bands can be readily detected in the controls, whereas no clear separation of c-fos+ bands is observed in ephrin-A3-/- mutants (e, $f$ ). Scale bar: $200 \mu \mathrm{m} . \mathrm{g}$ Quantification of c-fos-activated areas or separation areas between c-fos+ bands normalized to total AVCN areas in response to stimulation of a $16-\mathrm{kHz}$ tone, an $8-\mathrm{kHz}$ tone, or simultaneous 16- and 8$\mathrm{kHz}$ dual tones in control and ephrin-A3-/- mutant AVCN. Numbers on the bar indicate the sample size. Means \pm SDs are shown. **: $\mathrm{P}<0.01, * \star *: \mathrm{P}<0.001$, Welch's unequal variances t-test.
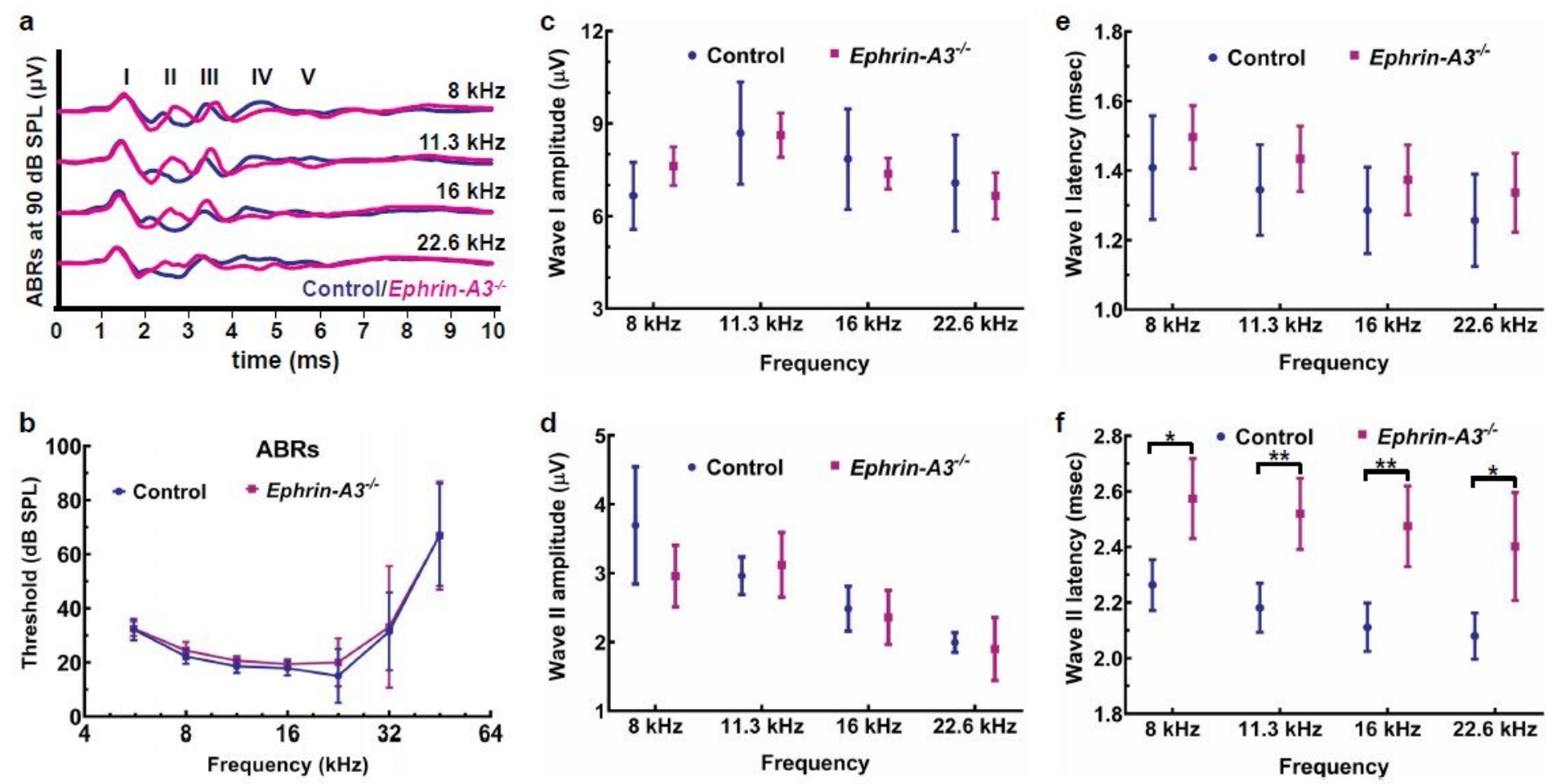

\section{Figure 6}

Ephrin-A3-/- mutants show normal hearing thresholds but a delayed wave II in auditory brainstem responses (ABRs). a Representative ABR recordings from a 6-week-old littermate control (blue traces) and an ephrin-A3-/- mutant (magenta traces) exposed to $8,11.3,16$, or $22.6 \mathrm{kHz}$ pure tone stimuli at intensity of $90 \mathrm{~dB}$ sound pressure level (SPL). Roman numerals mark the ABR waves. Wave I of ABRs are normal but Wave II are delayed in ephrin-A3-/- mutants compared to control littermates. b Average ABR thresholds for 7 littermate controls (blue) and 8 ephrin-A3-/- mutants (magenta) across frequency. No significant difference was observed between controls and ephrin-A3-/- mutants (Welch's unequal variances t-test, $P>0.1$ at all frequencies). c, d Average Wave I and Wave II amplitudes for 7 littermate controls (blue) and 8 ephrin-A3-/- mutants (magenta) in response to $8,11.3,16$, or $22.6 \mathrm{kHz}$ pure tone stimuli at intensity of $90 \mathrm{~dB}$ SPL. No significant difference of Wave I and Wave II amplitudes was observed between controls and ephrin-A3-/- mutants (Welch's t-test, $\mathrm{P}>0.4$ for both Wave I and Wave II at all frequencies). e, f Average Wave I and Wave II latencies for 7 littermate controls (blue) and 8 ephrinA3-/- mutants (magenta) in response to $8,11.3,16$, or $22.6 \mathrm{kHz}$ pure tone stimuli at intensity of $90 \mathrm{~dB}$ SPL. No significant difference of Wave I latencies was observed between controls and ephrin-A3-/- mutants 
(Welch's t-test, $\mathrm{P}>0.1$ at all frequencies). However, Wave II of ephrin-A3-/- mutants were significantly delayed when compared to controls (Welch's t-test, $*$ : $P<0.05, * *: P<0.01)$. Means $\pm S D$ s are shown in $(b-f)$.
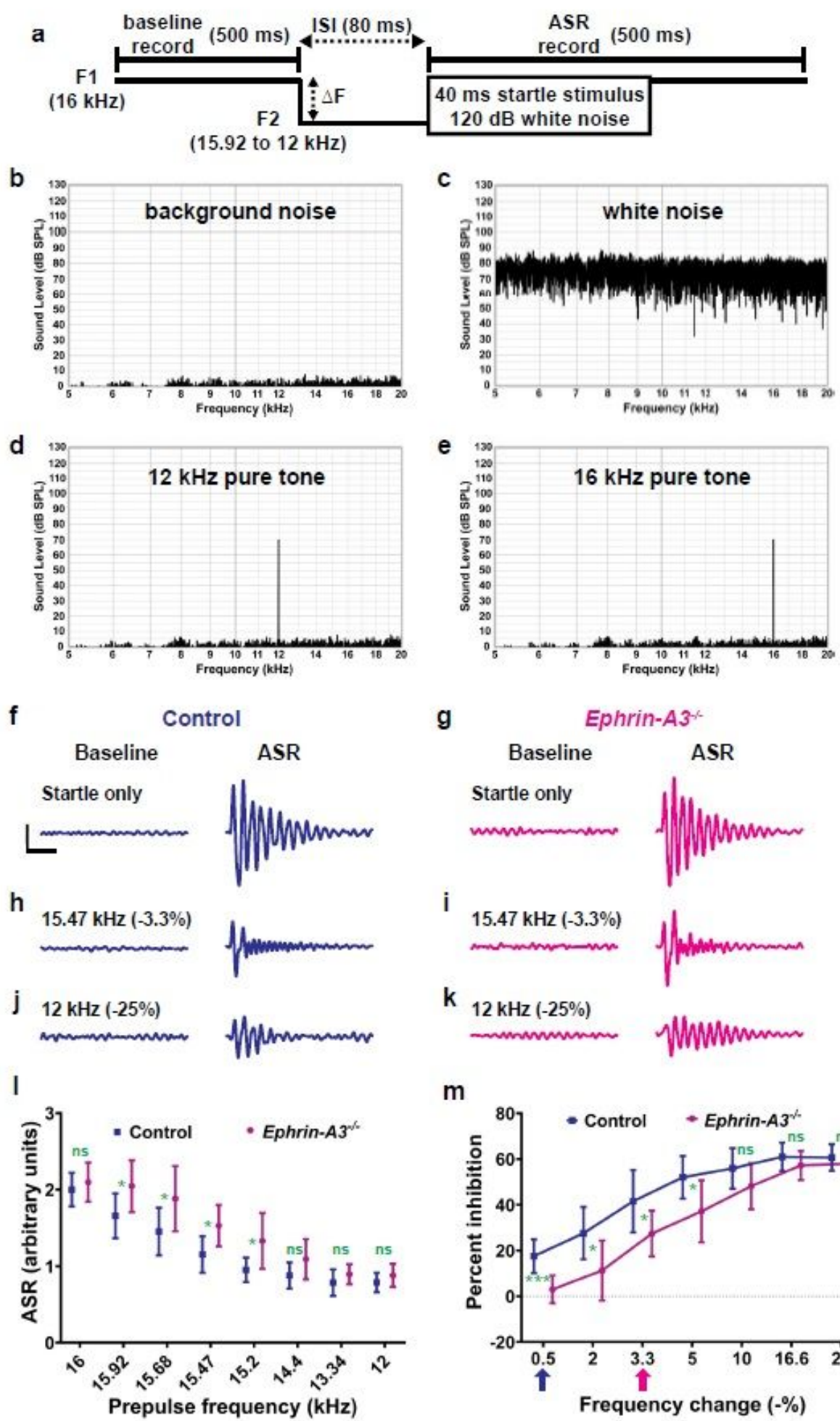

g

Ephrin-A3
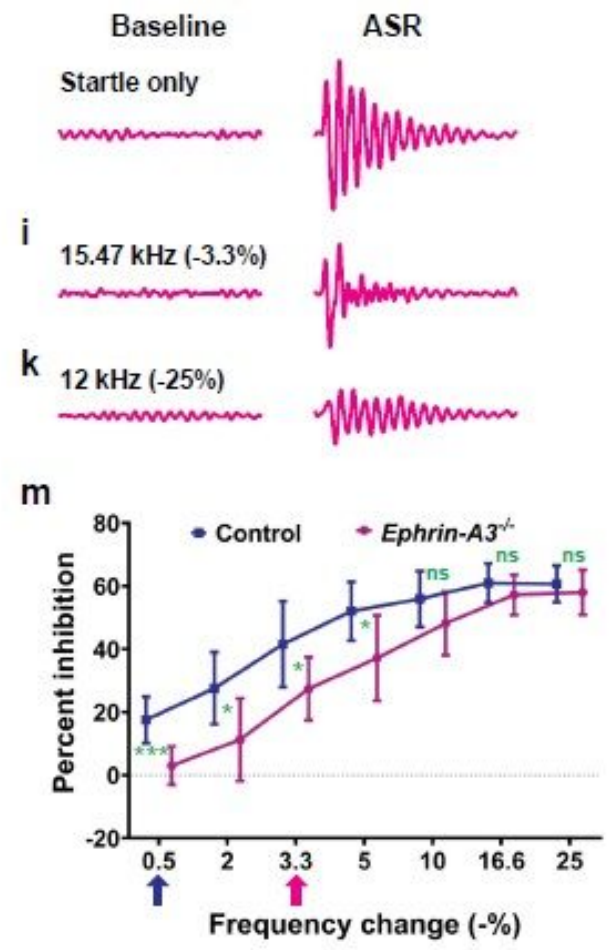

Figure 7

Ephrin-A3-/- mutants show impaired prepulse inhibition (PPI) of acoustic startle response (ASR) for detecting changes in sound frequencies. a Trial schematic for the ASR-based frequency discrimination assay. ISI: inter-stimulus interval; F1: background frequency; F2: prepulse frequency; $\Delta F$ : frequency 
change. b Background noise in the anechoic chamber. c White noise at 120dB SPL for the startle stimulus. $\mathrm{d} 16 \mathrm{kHz}$ tone at $70 \mathrm{~dB}$ SPL for the background frequency. e Prepulse frequencies were 7 tones from $15.92 \mathrm{kHz}$ to $12 \mathrm{kHz}$ at $70 \mathrm{~dB}$ SPL. Only the $12 \mathrm{kHz}$ tone was shown. f-k Representative recording traces of baseline activity and acoustic startle responses from a control (blue) and an ephrin-A3-/- mutant (magenta). Baseline or ASR traces represent the force measured during the first or the second 500-ms recording period. Scale bar, 1.0 arbitrary unit of force, $100 \mathrm{~ms}$. Both control and ephrin-A3-/- mice show a normal ASR in response to the startle stimulus. A change from the $16 \mathrm{kHz}$ background tone to prepulse tones $(15.47 \mathrm{kHz}, 3.3 \%$ change or $12 \mathrm{kHz}, 25 \%$ change) before the startle stimulus inhibited the ASR in both control and ephrin-A3-/- mice. However, the amount of inhibition elicited by the small $3.3 \%$ negative frequency change was less in ephrin-A3-/- mutants when compared to control. The large $25 \%$ frequency change elicits similar inhibition between control and ephrin-A3-/- mice. I Average ASR amplitudes for 8 controls (blue) and 6 ephrin-A3-/- mutants (magenta) for each trial type. Means \pm SDs are shown. No significant difference of ASR amplitudes was observed between controls and ephrin-A3-/- mutants in response to the startle-only stimulus ( $P=0.47$, Welch's t-test). The ASR magnitude elicits by small negative frequency changes (0.5-5\%) was significant smaller in controls than in ephrin-A3-/- mutants (ns: no significance, *: $\mathrm{P}<0.05$, Two-way ANOVA with post-hoc Welch's t-test). $m$ Average percent inhibition of the ASR elicited by prepulse frequency changes at various magnitudes for 8 controls (blue) and 6 ephrin-A3-/mutants (magenta). Means \pm SDs are shown. Ephrin-A3-/- mutants show significant reduced prepulse inhibition for small negative frequency changes (0.5-5\%), indicating that an impaired ability to detect small frequency changes. Arrows indicate discrimination threshold, the smallest frequency change that elicited a significant inhibition of the ASR $(p<0.05$, one-way Welch's t-test compared to zero frequency change). Ephrin-A3-/- mutants have an elevated discrimination threshold. 


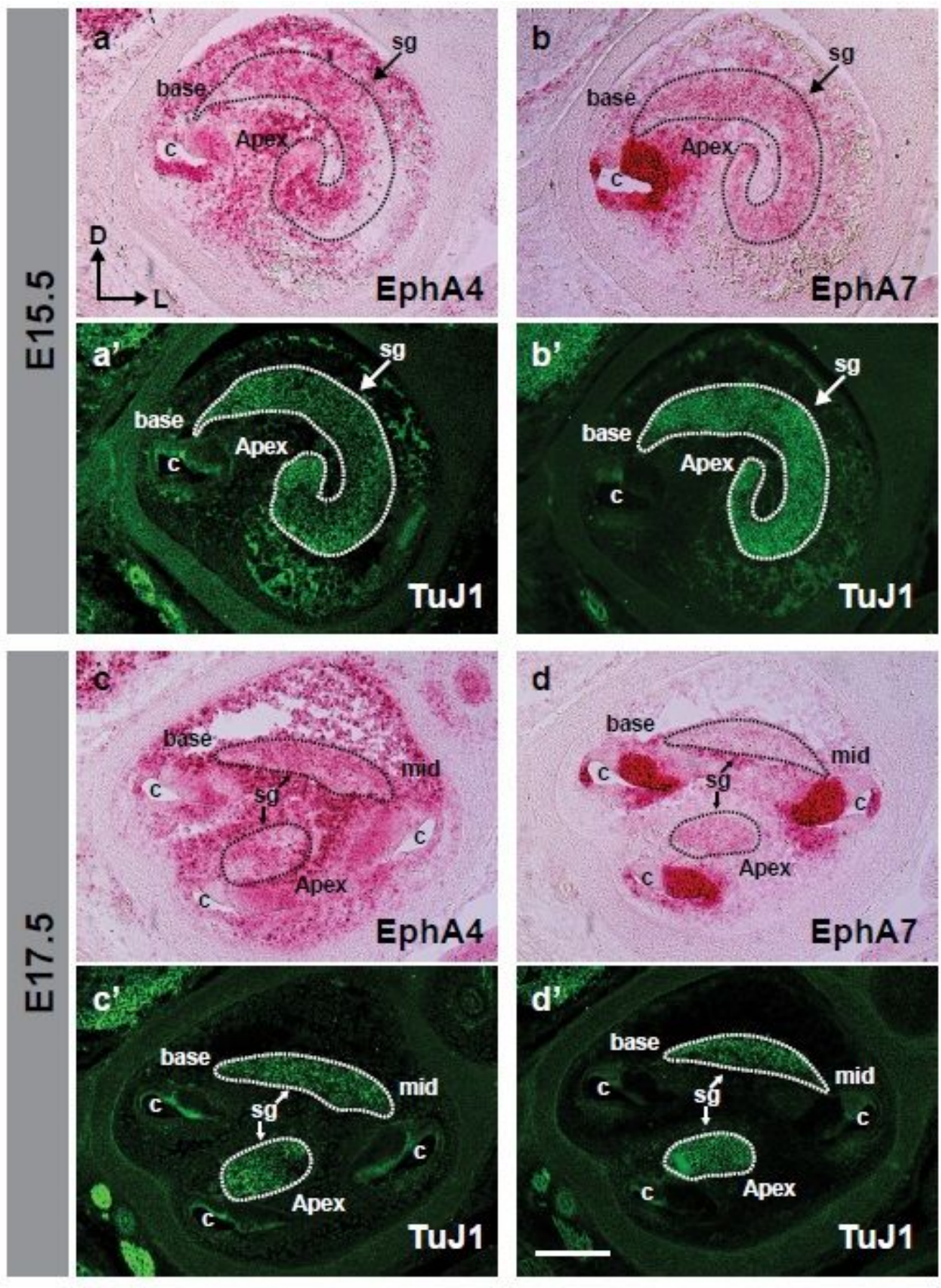

Figure 8

EphA receptors are expressed in developing spiral ganglion neurons (SGNs). Expression of EphA4 and EphA7 receptors in E15.5 or E17.5 cochleae were detected by RNAScope ${ }^{\circledR}$ in situ hybridization using an AP-based chromogen (red). The cochlear sections were co-stained with TuJ1 to mark the spiral ganglion (sg). The spiral ganglion was outlined with dashed lines based on TuJ1 staining. Both EphA4 and EphA7 receptors are expressed in developing SGNs. c: cochlear duct. The axis in (a) indicates the orientation of all the sections in the figure. D, dorsal; L, lateral. Scale bar: $200 \mu \mathrm{m}$. 

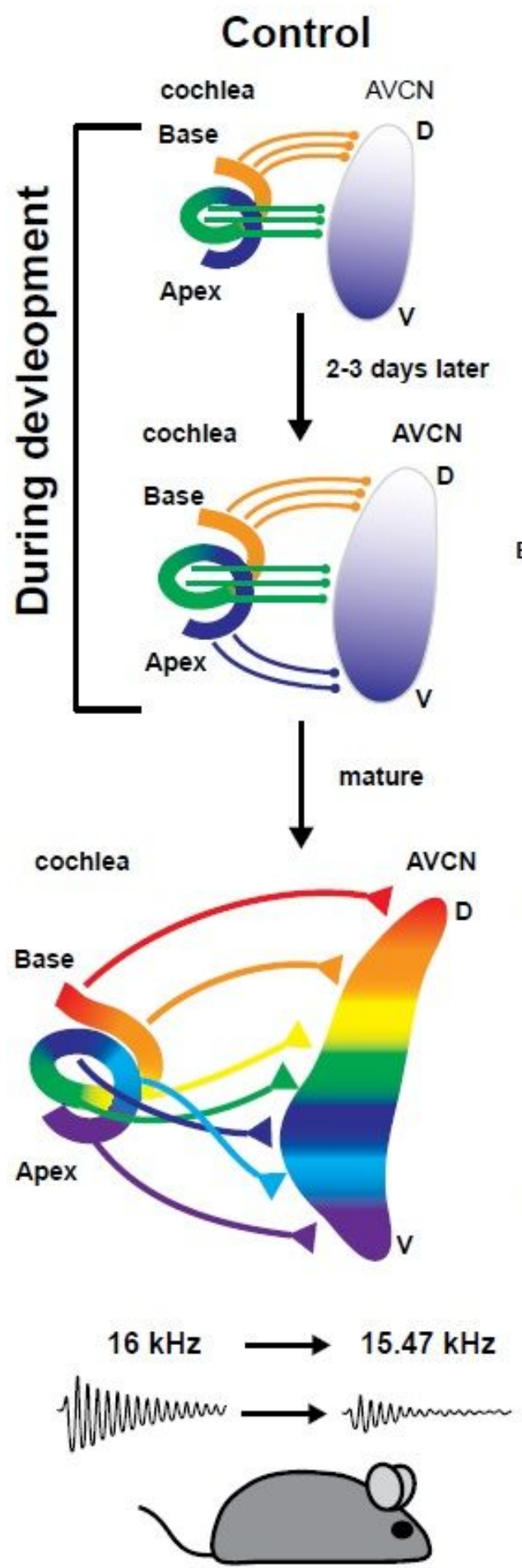

Normal PPI (Normal frequency discrimination)

\section{Ephrin-A3\%}
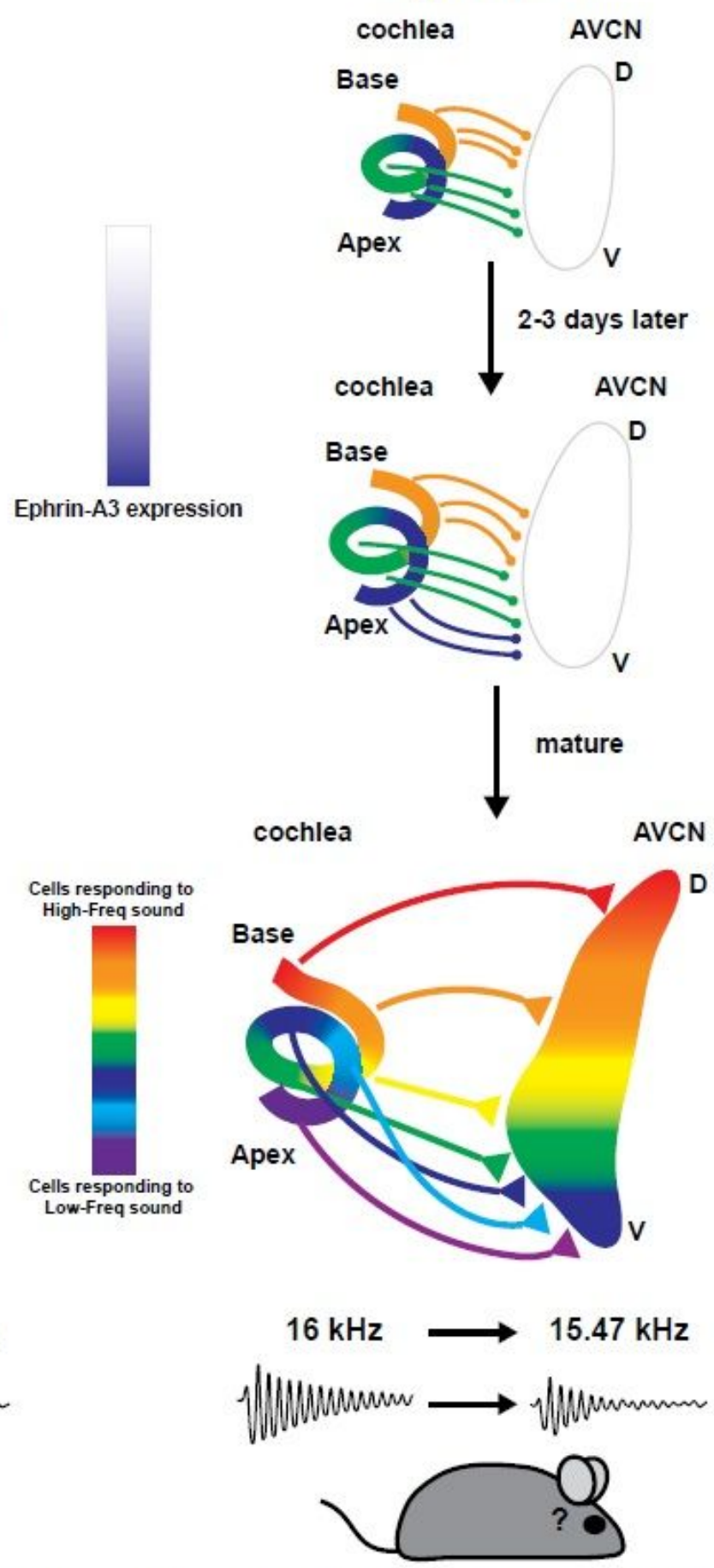

reduced PPI (impaired frequency discrimination)

\section{Figure 9}

Proposed model for ephrin-A3's role in $\mathrm{CN}$ tonotopic mapping and sound discrimination. During embryonic development, ephrin-A3 is expressed in the $\mathrm{CN}$ in a ventral to dorsal descending gradient. Neurogenesis of spiral ganglion neurons (SGNs) occurs in a basal to apical progression along the cochlea. ANFs of the early-born SGNs from basal and middle regions of the cochlea innervate the CN 1-3 days earlier than ANFs of the late-born apical SGNs. An intermediate to high concentration of ephrin-A3 in 
the ventral region of the $\mathrm{CN}$ prevents these early-arriving ANFs from stabilizing their terminals in this territory and innervate areas more dorsally. 2-3 days later, the response of ANFs to ephrin-A3 decreases, allowing late-arriving apical ANFs to target to the ventral portion of the $\mathrm{CN}$. When the auditory system matures, the cochlea and $\mathrm{CN}$ establish a normal tonotopic arrangement of neuronal connectivity where basal ANFs project to the dorsal part of the $\mathrm{CN}$ and apical ANFs target to the ventral side of the $\mathrm{CN}$, forming precise isofrequency bands to allow animals to discriminate sounds even with subtle frequency changes. In ephrin-A3-/- mutants, early-arriving ANFs from the base and middle of the cochlea may start to terminate in areas more ventrally in the $\mathrm{CN}$ due to a lack of ephrin-A3 in the ventral region, leading to a degraded tonotopic map and impaired ability to detect sound frequency changes when the animals matures. 